\title{
U.S. Geological Survey Quality-Assurance Plan for Surface-Water Activities in Kansas, 2015
}

Open-File Report 2015-1074 



\section{U.S. Geological Survey Quality-Assurance Plan for Surface-Water Activities in Kansas, 2015}

By C. Craig Painter and Brian L. Loving

Open-File Report 2015-1074 


\title{
U.S. Department of the Interior SALLY JEWELL, Secretary
}

\section{U.S. Geological Survey \\ Suzette M. Kimball, Acting Director}

\author{
U.S. Geological Survey, Reston, Virginia: 2015
}

For more information on the USGS - the Federal source for science about the Earth, its natural and living resources, natural hazards, and the environment—visit http://www.usgs.gov or call 1-888-ASK-USGS.

For an overview of USGS information products, including maps, imagery, and publications, visit http://www.usgs.gov/pubprod/.

Any use of trade, firm, or product names is for descriptive purposes only and does not imply endorsement by the U.S. Government.

Although this information product, for the most part, is in the public domain, it also may contain copyrighted materials as noted in the text. Permission to reproduce copyrighted items must be secured from the copyright owner.

Suggested citation:

Painter, C.C., and Loving, B.L., 2015, U.S. Geological Survey quality-assurance plan for surface-water activities in Kansas, 2015: U.S. Geological Survey Open-File Report 2015-1074, 33 p., http://dx.doi.org/10.3133/ofr20151074.

ISSN 2331-1258 (online) 


\section{Contents}

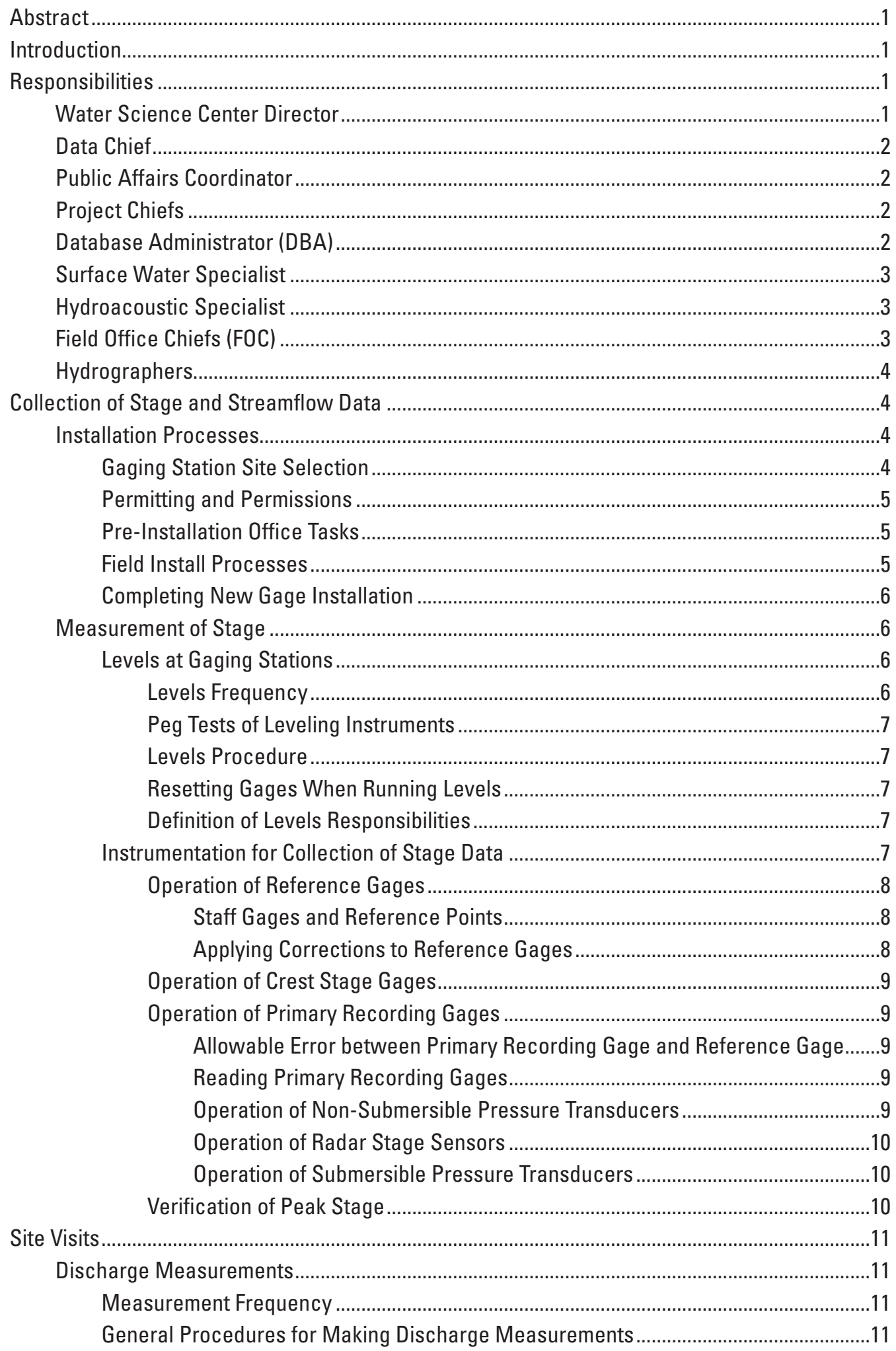


Check Measurements ................................................................................................12

Hierarchy for Things to Change When Making a Check Measurement of an ADCP Measurement: ...........................................................................12

Hierarchy for Making a Check Measurement of a Midsection ADV Measurement:........................................................................................12

Making A Check Measurement of a Midsection Current Meter

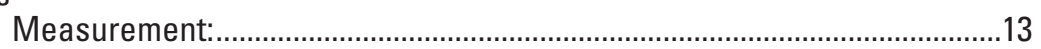

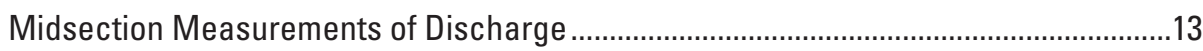

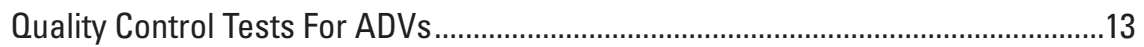

Quality Control Tests for Mechanical Current Meters.............................................13

General Rules for Midsection Discharge Measurements ........................................13

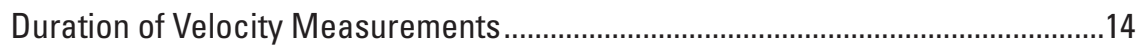

Minimum Depth for Midsection Discharge Measurements ...................................14

Measurement Depths at a Given Vertical..............................................................14

Rating of Midsection Discharge Measurements .................................................14

Midsection Measurements from Ice Cover …………………...............................15

Midsection Methods for Measurements under Ice Cover .............................15

Midsection Measurement Using an ADCP.......................................................15

Moving Boat Measurement Using an ADCP ...............................................................15

Instrument Testing and Quality Control.............................................................15

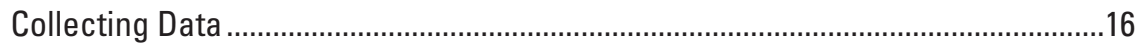

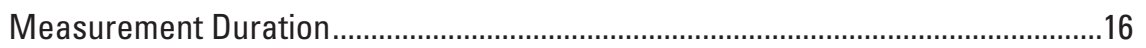

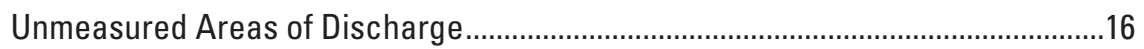

Multiple Channel Considerations .........................................................................16

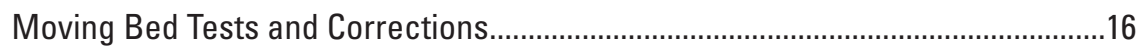

Use of Collected Transect Data.............................................................................17

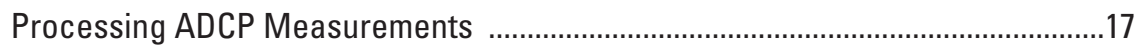

Application of Extrapolation Methods...................................................................17

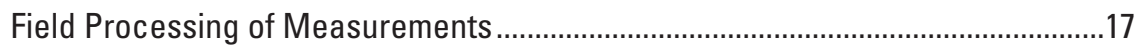

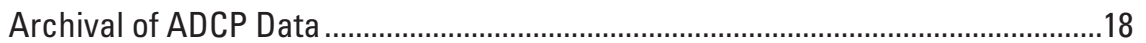

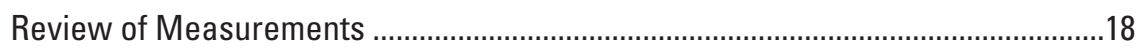

Measurement Using Parshall-Flume .........................................................................18

Volumetric Measurement.............................................................................................18

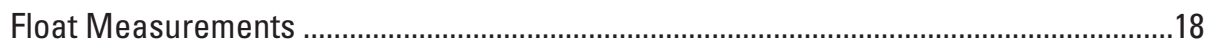

Indirect Measurements of Discharge ......................................................................

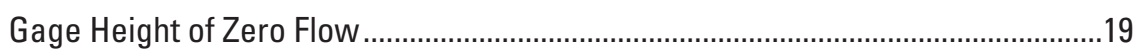

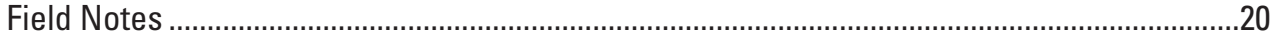

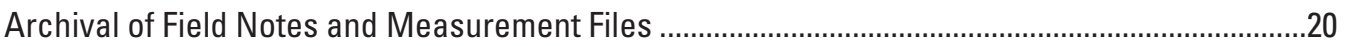

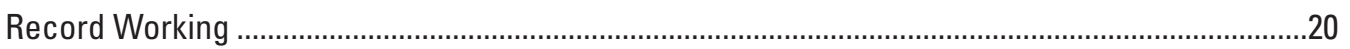

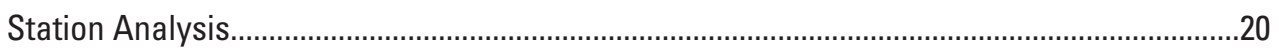

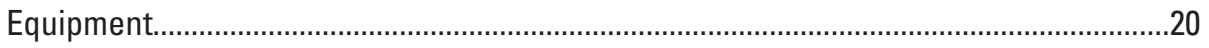

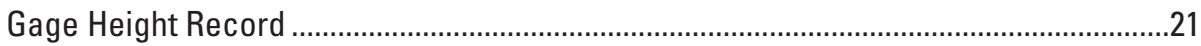

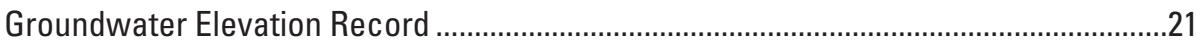

Datum and Gage Height Corrections..........................................................................

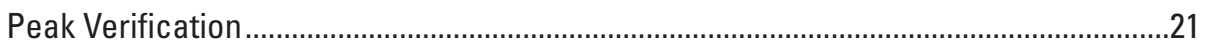

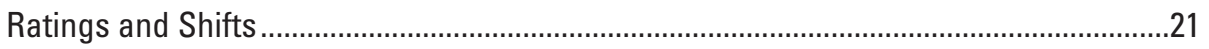




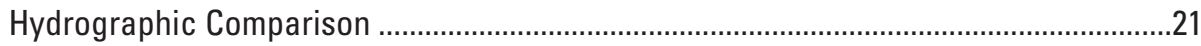

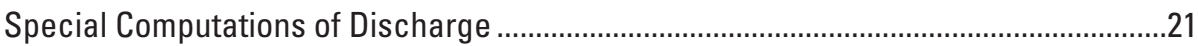

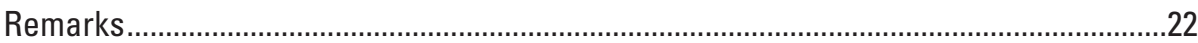

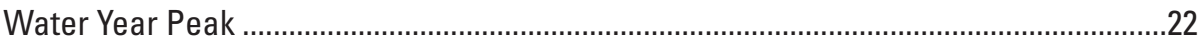

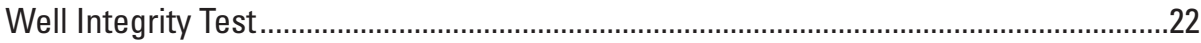

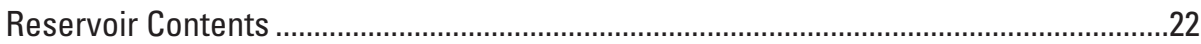

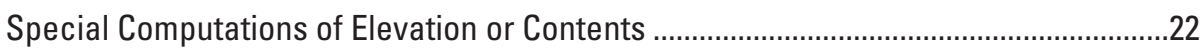

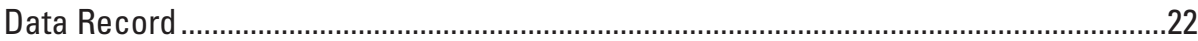

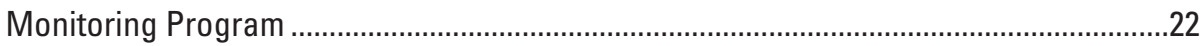

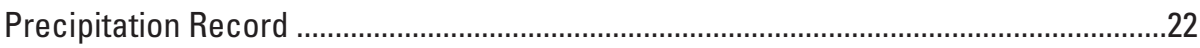

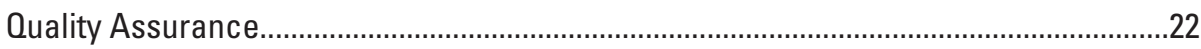

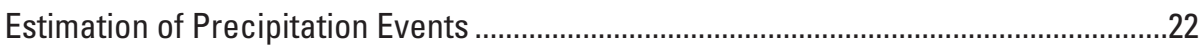

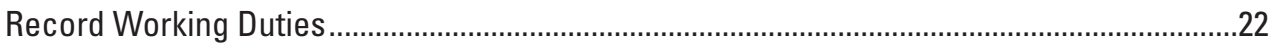

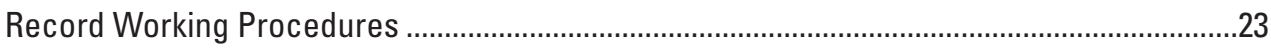

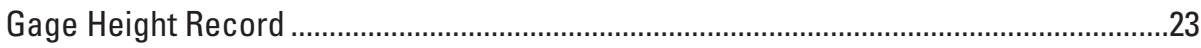

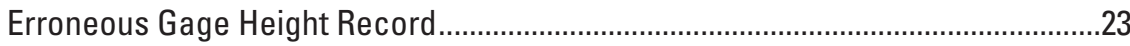

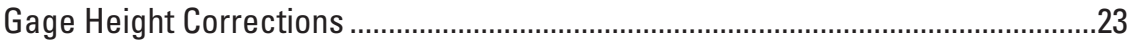

Single-Point Gage Height Corrections ……………….............................................

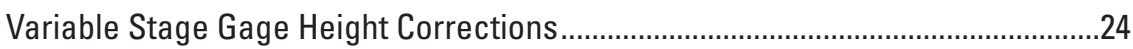

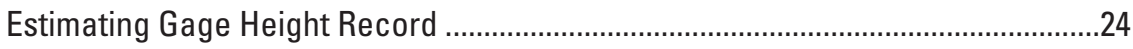

Peak Gage Height Record Obtained From Auxiliary Data.........................................24

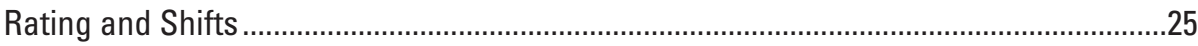

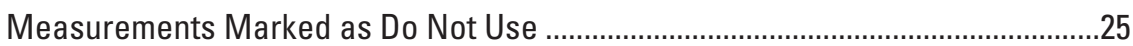

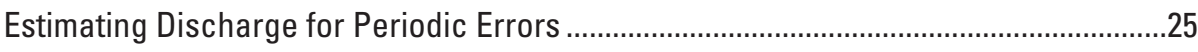

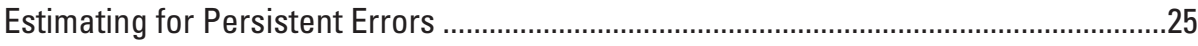

Estimating Discharge Because of Backwater From Ice .......................................25

Ice Damming Upstream From the Gaging Location ..............................................26

Temporary Loss of Discharge to Ice Storage.......................................................26

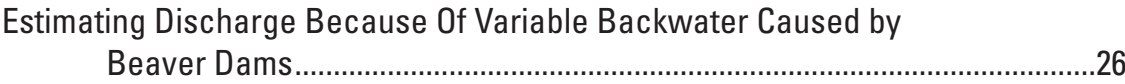

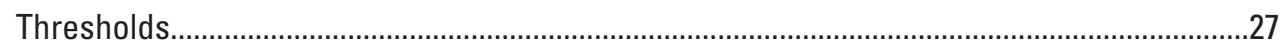

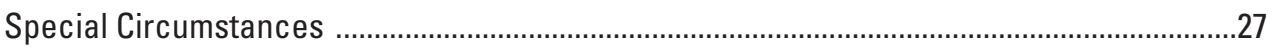

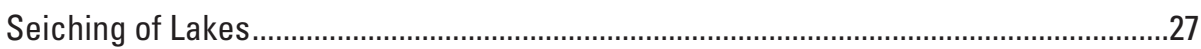

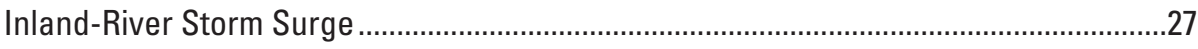

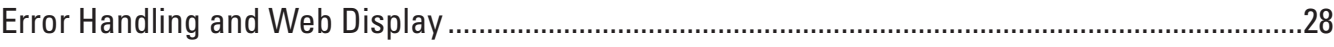

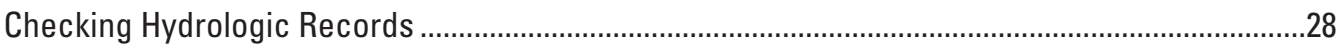

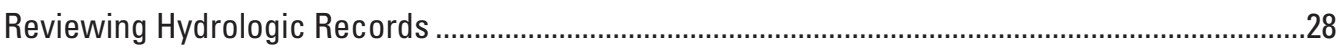

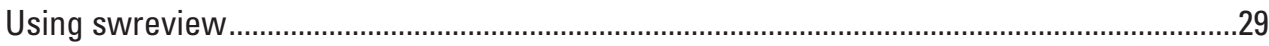

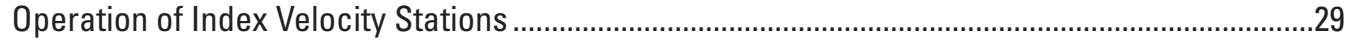

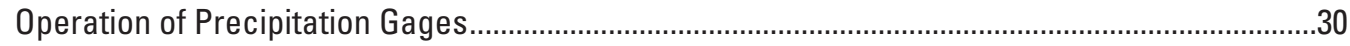

Field Procedures for Precipitation Gage Operation.............................................................30

Working Precipitation Gage Records ................................................................................

Estimating Precipitation Record...............................................................................

Checking Precipitation Gage Records ……………….......................................................

Reviewing Precipitation Gage Records .............................................................................30

Storing and Archival of Hydrologic Data and Related Metadata ....................................................30 


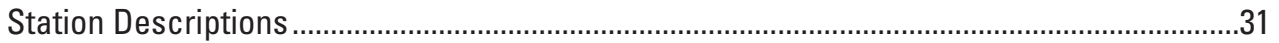

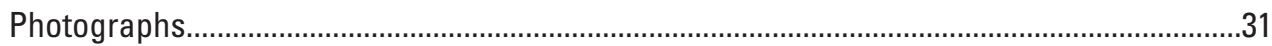

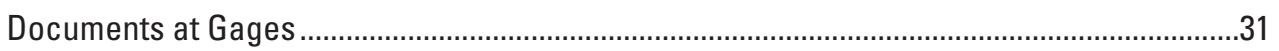

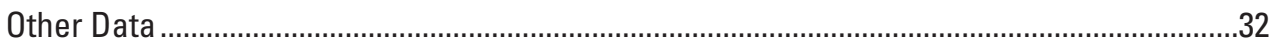

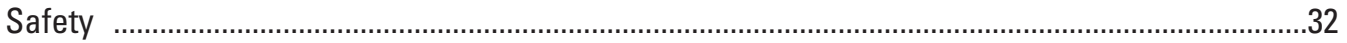

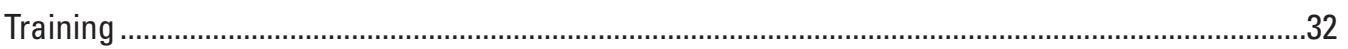

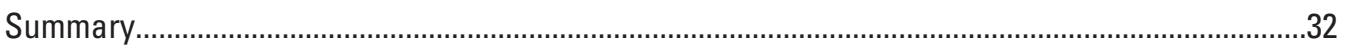

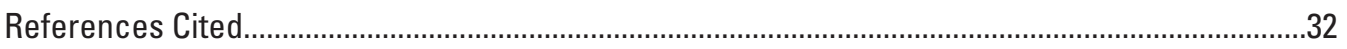

Memorandums Cited .........................................................................................................

\section{Abbreviations and Acronyms}

$\begin{array}{ll}\text { ADAPS } & \begin{array}{l}\text { U.S. Geological Survey National Water Information System Automatic Data } \\ \text { Processing System }\end{array} \\ \text { ADCP } & \text { Acoustic Doppler Current Profiler } \\ \text { ADR } & \text { Annual Data Report } \\ \text { ADV } & \text { Acoustic Doppler Velocimeter } \\ \text { ADVM } & \text { acoustic Doppler velocity meters } \\ \text { BARC } & \text { Brian's Aid for Rating Creating computer program } \\ \text { CAP } & \text { Culvert Analysis Program computer program } \\ \text { CSG } & \text { Crest Stage Gage } \\ \text { ft3/s } & \text { cubic foot per second } \\ \text { DBA } & \text { database administrator } \\ \text { DCP } & \text { Data Collection Platform } \\ \text { DECODES } & \text { Device Conversion and Delivery System } \\ \text { EXTRAP } & \text { U.S. Geological Survey extrapolation computer program } \\ \text { FOC } & \text { Field Office Chief } \\ \text { g/L } & \text { grams per liter } \\ \text { Go2 } & \text { A utility to automatically determine when site visits are needed } \\ \text { GPS } & \text { Global Positioning System } \\ \text { GWSI } & \text { U.S. Geological Survey Ground Water Site Inventory } \\ \text { GZF } & \text { Gage-height of zero flow } \\ \text { HIF } & \text { U.S. Geological Survey Hydrologic Instrumentation Facility }\end{array}$




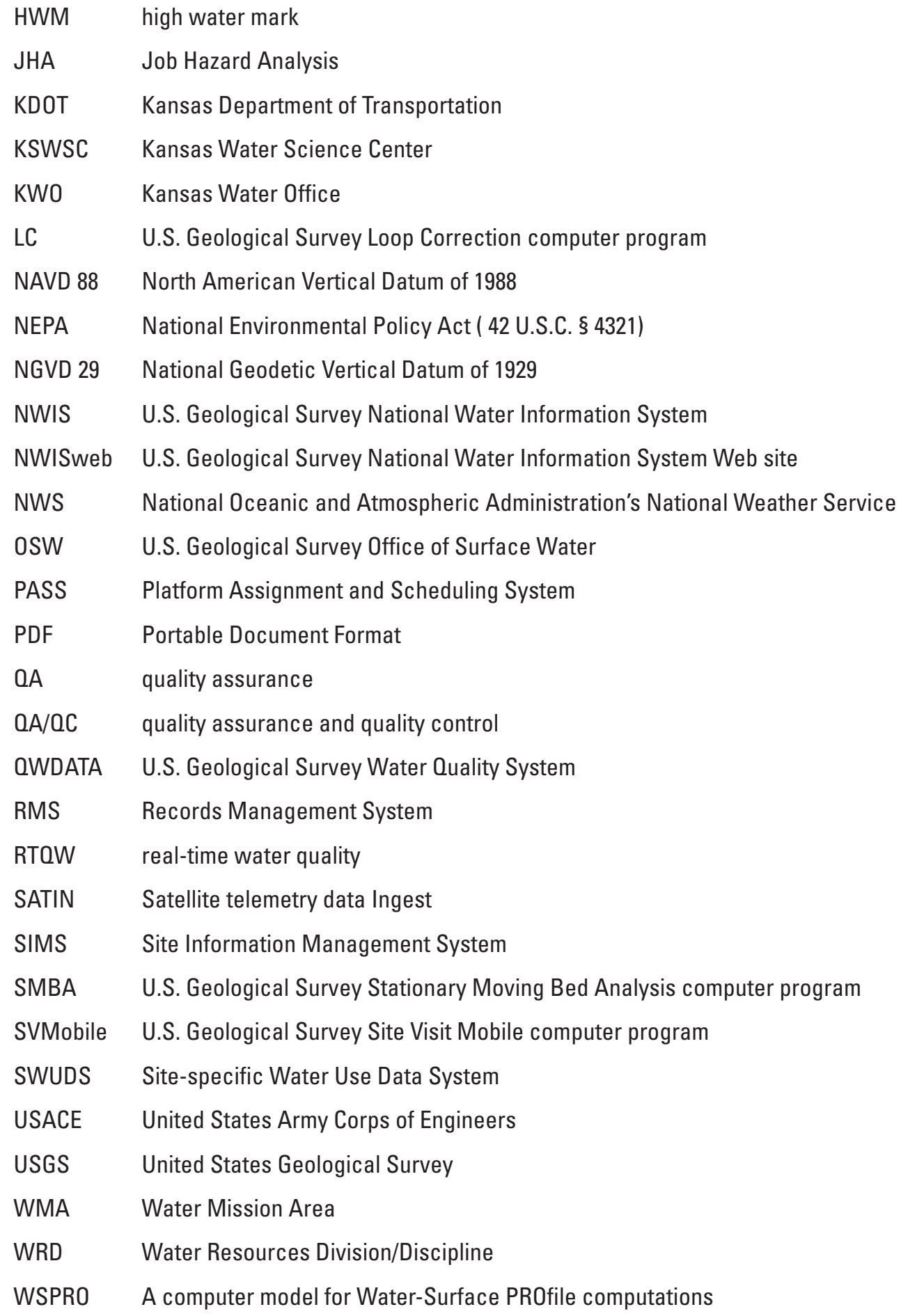





\title{
U.S. Geological Survey Quality-Assurance Plan for Surface-Water Activities in Kansas, 2015
}

\author{
By C. Craig Painter and Brian L. Loving
}

\begin{abstract}
This Surface Water Quality-Assurance Plan documents the standards, policies, and procedures used by the Kansas Water Science Center (KSWSC) of the U.S. Geological Survey (USGS) for activities related to the collection, processing, storage, analysis, and publication of surface-water data.
\end{abstract}

\section{Introduction}

The U.S. Geological Survey was established by an act of Congress on March 3, 1879, to provide a permanent Federal agency to "examine the geological structure, mineral resources, and products of the national domain" (43 U.S.C. § 31). Surface-water activities of the USGS in Kansas are part of the Survey's Water Mission Area's (WMA, formerly Water Resources Discipline or WRD) overall mission of appraising the Nation's water resources. Surface-water information, including streamflow, stream stage, and lake and reservoir stage and contents, are used at the Federal, State, and local levels for resources planning and management.

The purpose of this Surface Water Quality-Assurance (QA) Plan is to establish and document the responsibilities, standards, policies, and procedures used by the KSWSC for activities related to the collection, processing, storage, analysis, and publication of surface-water data.

This plan identifies responsibilities for ensuring that stated policies and procedures are accomplished. The plan also serves as a guide for all KSWSC personnel involved in surface-water activities, and as a resource for identifying memorandums, publications, and other literature that describe, in more detail, associated techniques and requirements.

The scope of this report includes discussions of the policies and procedures followed by the KSWSC for the collection, processing, analysis, storage, and publication of surface-water data. Specific types of surface-water data include stage, and streamflow. In addition, issues related to the management of the database and employee safety and training are presented. Although procedures and products of interpretive projects are subject to the criteria presented in this report, specific interpretive projects may require a separate quality-assurance plan. The guidelines and quality-assurance requirements for groundwater and water quality are detailed in quality-assurance plans for these disciplines found at http:// pubs.er.usgs.gov/publication/ofr20141060 and http://pubs. er.usgs.gov/publication/ofr20141233 respectively.

This QA plan is reviewed and revised at least once every 3 years to document current responsibilities, methods, and ongoing procedural improvements.

\section{Responsibilities}

Surface-water-data collection and quality assurance are a continuous and active process. Achieving and maintaining high-quality standards for surface-water data are accomplished by specific actions carried out by specific persons. Errors and deficiencies can result when individuals fail to carry out their responsibilities. Clear and specific statements of responsibilities promote an understanding of each person's duties in the overall process of assuring surface-water data quality.

The following is a list of responsibilities of USGS personnel involved in the collection, processing, storage, analysis, and publication of surface-water data in Kansas.

\section{Water Science Center Director}

1. Managing and directing the USGS program in Kansas, including all surface-water activities.

2. Ensuring that surface-water activities meet the needs of the Federal Government, the USGS, State and local agencies, other cooperating agencies, and the general public.

3. Ensuring that all aspects of this QA plan are understood and followed by USGS personnel in Kansas. This is accomplished by the direct involvement of the Director, or through clearly stated delegation of this responsibility to other USGS personnel in the State.

4. Providing final resolution of any conflicts or disputes related to USGS surface-water activities in Kansas. 
5. Keeping subordinates briefed on procedural and technical communications from Regional Offices and Headquarters.

6. Performing quarterly project technical reviews.

7. Ensuring that all publications and other technical communications released by the KSWSC are accurate and are in accordance with all current USGS policies.

\section{Data Chief}

1. The overall operation of the Hydrologic Data Management Section, certain surface-water projects and the Data Section field offices in Hays, Lawrence, and Wichita.

2. The day-to-day operation of the surface-water datacollection network.

3. Ensuring that all data collected and processed by the KSWSC Data Section follow USGS and KSWSC standards and procedures as defined by the latest edition of the district's quality assurance plans.

4. Updating the Surface Water QA Plan for Kansas.

5. Ensuring that employees receive the necessary training for safe and proper data collection.

6. Selecting new gage sites.

7. Approving equipment prior to use in network sites.

8. Recommending need for indirect measurements.

9. Coordination during floods.

10. Representing the Data Section and surface-water issues and concerns on the KSWSC Senior Staff.

11. Managing the Data Section projects and budgets, including income from data-collection agreements with USGS and other agencies, and other sources, and expenditures by the section including staffing and purchases.

12. Developing new program by finding funding for new gages and projects to enhance and expand the collection and interpretation of hydrologic data in Kansas.

13. Overseeing personnel issues in the Data Section including hiring, term employee appointments and renewals, disciplinary actions, awards, promotions and overall staffing.

14. Ensuring that the Data Section has enough equipment, of the proper type and quality, to keep the gages operating properly at all times, and there is enough equipment for the field staff to perform all needed data collection and maintenance under all conditions.
15. Annually obtaining right-of-way access permits from all six Kansas Department of Transportation (KDOT) Districts. These permits allow USGS staff and vehicles to work and park in the state-owned highway right-of-ways across Kansas to collect data and maintain gages, as well as to access roads closed because of floodwaters.

\section{Public Affairs Coordinator}

1. Maintaining media contacts during major flood, drought, or other hydrologic events.

\section{Project Chiefs}

1. Ensuring that surface-water data collected, computed, or interpreted as part of their project is done in accordance with all applicable QA guidelines.

\section{Database Administrator (DBA)}

1. Maintaining surface-water, water-quality, and groundwater databases.

2. Ensuring the integrity of surface-water, water-quality, and groundwater databases.

3. Maintaining operation of the Kansas section of the National Water Information System (NWIS), to include redirecting operations to a system backup when problems occur, making sure system is updating properly and displaying all stations, and adding or discontinuing stations as needed.

4. Maintaining SATIN and Sentry systems that process real-time data.

5. Maintaining NWISweb, the system that displays NWIS data on the Internet.

6. Maintaining the real-time water-quality (RTQW) web system.

7. Maintaining ADAPS, QWDATA, SWUDS, and GWSI computer programs and communicating problems to the information technology site administrator.

8. Maintaining the metadata (previously referred to as the Annual Data Report's Manuscript) for display in NWISweb.

9. Updating and maintaining peak-flow file.

10. Handling data requests related to surface water, water quality and groundwater. 


\section{Surface Water Specialist}

1. Reviewing indirect discharge measurements.

2. Ensuring that the peak-flow file is updated annually, and reviewing the data in that file.

3. Approving design and installation of artificial controls.

4. Providing technical assistance for surface-water datacollection and computation activities.

5. Providing technical assistance for data analysis and interpretation of surface-water investigations.

6. Coordinating some activities including nonroutine data collection efforts (such as indirect measurements and synoptic studies), and providing special computations of historical data statistics (such as streamflow duration and recurrence intervals) upon request.

\section{Hydroacoustic Specialist}

1. Reviewing and revising KSWSC policies regarding hydroacoustic instruments for relevancy and compliance with Office of Surface Water standards.

2. Communicating new developments in hydroacoustic instrument use, software and firmware version updates, and training opportunities to users within the KSWSC.

3. Documenting the testing of all new and repaired hydroacoustic equipment, as well as performing instrument tests on regularly scheduled intervals.

4. Providing technical assistance for users experiencing problems or persistent errors using hydroacoustic instruments.

\section{Field Office Chiefs (FOC)}

1. Assigning workloads for their staff to complete scheduled work.

2. Overseeing personnel issues for assigned staff, in coordination with the Data Chief, and WSC and Regional Human Resources staff.

3. Providing appropriate staff training.

4. Collecting and completing documentation for new gage sites.
5. Inspecting and approving new gage site designs and installations.

6. Inspecting all gages in their area of responsibility, annually.

7. Ensuring that gage equipment is properly installed, serviced, and calibrated.

8. Ensuring that an adequate amount of spare equipment (generally 10 percent of what is installed) is always on hand.

9. Ensuring that proper measuring equipment is used for given flow conditions, and that annual inspection of measuring equipment is completed.

10. Reviewing data collected during site visits, and site visit planning and execution for efficiency and effectiveness.

11. Ensuring that station levels are run properly and at an appropriate frequency.

12. Reviewing real-time data in their area of responsibility daily using NWISweb and the go2 computer program for proper operation of all streamflow-gaging stations, crest-stage gages, reservoir gages, groundwater-level gages, and water-quality monitoring stations in their area of responsibility.

13. Monitoring status of continuous record processing throughout the year, ensuring that records are approved in ADAPS before data are 150 days old (unless more time is needed to accurately compute the record of data).

14. Reviewing data and documents that are only periodically updated such as Station Descriptions, Job Hazard Analyses, and metadata about records and stations that used to be in the Annual Data Report manuscripts.

15. Participating in review of records from their field office, and others, as assigned.

16. Ensuring that all data collected and processed by their field office are done according to USGS and KSWSC standards and procedures outlined in the current quality assurance plans.

17. Communicating with staff and the Flood Coordinator during floods.

18. Coordinating with the Data Chief and Project Chiefs to ensure that personnel are available for project datacollection activities when needed.

19. Ensuring that the staff in their office has the necessary safety training and equipment, and follow safety policies at all times. 


\section{Hydrographers}

1. Collecting and processing field data.

2. Daily review of real-time data for assigned sites, and when they are in the office, rectifying errors by editing, estimating and qualifying/masking data as necessary.

3. Recognizing when scheduled and unscheduled field work is necessary and performing work in a safe, effective, and efficient manner.

4. Compiling, computing, and quality assuring assigned records.

5. Checking and reviewing assigned records for accuracy.

6. Updating site specific safety plans for assigned sites (for example, Job Hazard Analysis and Traffic Control Plan) based on guidance from the district Safety Coordinator.

7. Maintaining all field equipment, including vehicles and tools, assigned to or used by them.

8. Keeping station levels current at gages assigned to them.

9. Installing and maintaining gage equipment.

10. Following USGS and WSC safety policies and traffic control plans.

11. Coordinating field work with their Field Office Chief, Data Chief, Flood Coordinator, and any Project Chiefs they are assigned to perform work for.

\section{Collection of Stage and Streamflow Data}

Many of society's daily activities, including industry, agriculture, energy production, waste disposal, and recreation are closely linked to streamflow and water availability; therefore, reliable surface-water data are necessary for planning and resource management. The collection of stage and streamflow data at hydrologic gaging stations (referred to in the remainder of this document as gaging stations) is a primary component of the USGS long-term continuous data collection operation in Kansas.

The primary objective of operating a gaging station is generally to obtain a continuous record of stage and discharge at the site (Carter and Davidian, 1968, p. 1). A continuous record of stage is obtained by installing instruments that measure and record water-surface elevation in the stream or reservoir. Discharge measurements are made at periodic intervals in streams to define or verify the stage-discharge relation, and to define the timing and magnitude of variations in that relation. Detailed information on procedures and requirements described in this quality assurance plan are found in the references cited in this report.

It is the policy of the KSWSC that all personnel involved in the collection of stage and discharge data are informed of and follow the surface-water data-collection policies and procedures established by the KSWSC and USGS headquarters offices such as the Office of Surface Water and the Water Mission Area (formerly Water Resources Division).

\section{Installation Processes}

Proper installation and maintenance of gaging stations is critical for ensuring quality in streamflow-data collection and analysis. Effective site selection, correct design and construction, and regular maintenance of a gage can make the difference between efficient and accurate determination of discharge, and time-consuming, poor estimations of discharge. The person responsible for overseeing the details of the installation process is the Field Office Chief whose area the gage is located in. Field Office Chiefs may delegate any tasks, so long as they ensure the adequate completion of those tasks.

\section{Gaging Station Site Selection}

Sites for installation of gaging stations are selected with the intent to meet the purpose of each specific gage. Additionally, sites are selected with the intent of achieving, to the greatest extent possible, ideal hydraulic conditions. Criteria that describe the ideal gaging station site are listed in Sauer and Turnipseed (2010, p. 41). These criteria include unchanging natural controls that promote a stable stage-discharge relation, a satisfactory reach for measuring discharge throughout the range of stage, and the means for safe and efficient access to the gage and measuring location.

The individual responsible for selecting sites for new gaging stations is the Data Chief. The process of site selection includes discussion with cooperators and project chiefs on the purpose of the gage, analysis of the vicinity with the use of maps and aerial photography, available information on historic peaks from the National Weather Service or other sources, onsite reconnaissance, and a database search to determine if discontinued stations existed in the area. Onsite examination should determine the location of controls, hydraulic and hydrologic impacts associated with tributaries and diversions, access issues, factors affecting installation such as bridge rail design and suitability of the various stage sensors available, safety concerns such as shoulder width and traffic conditions, and where to locate the gage (including height) to avoid damage to the gage and other on-site equipment from floods. The traffic control plan (Marintzer and Foster, 2014) should be referenced to ensure that high-flow measurements can safely be made. Planning for extreme high-water measurements includes locating an auxiliary site suitable for measurements and locating possible locations for launching a boat if access roads or the bridge could be submerged. Factors to plan for at 
the gaging site include consideration of the optimum instrument for measurement of stage, direction of path for clear satellite transmissions that could affect satellite assignment, and clear path of sunlight for the solar panel. Latitude and longitude should be determined at the location using Global Positioning System (GPS) or digital maps. If a site is intended to be a discharge site, a temporary measuring point could be established and discharge measurements can be collected as needed to begin development of the stage-discharge rating before the gage is installed.

\section{Permitting and Permissions}

As soon as a location has been determined to be a suitable gaging site, the permitting process should begin. Permits required to install a gage can include KDOT Right of Way permit for locating the gage house near the roadway, KDOT Attachment to Bridge permit for installation of wire weight and radar gages, or similar written permissions from the county engineer or private landowner. At a minimum, permission must be in the form of an email from an appropriate representative of the property owner, stating that the USGS has permission to install, maintain, and access a gage at the location. The USGS requires that all new gage installations receive a National Environmental Policy Act permit issued by the bureau Environmental Manager and approved by the Center Director. The responsibility for ensuring proper documentation of agreements with property owners (both private and government) is held by the Field Office Chief. All written permissions are then given to and stored by the Data Chief.

\section{Pre-Installation Office Tasks}

1. Determine legal description, county hydrologic unit, stream mile (if available) [DBA].

2. Determine drainage area and contributing drainage area [GIS Specialist or FOC].

3. Station is entered into the NWIS site file [DBA].

4. PASS assignment is requested for sites using satellite transmitted data [DECODES Specialist].

5. Site is set up in NWIS, SIMS, RMS and NWISweb, and a directory is created in the electronic data archive [DBA].

6. Job Hazard Analysis (JHA) is drafted using notes and photos from field reconnaissance combined with maps and aerial photos [Hydrographer assigned to operate station].

7. A preliminary Station Description is drafted with the data available describing the anticipated installation [Hydrographer assigned to operate station].
8. WSC and assigned field office SV Mobile files and GPS navigation files are to be updated [FOC].

9. Notify other agencies that may have an interest in using the data from the new gage (for example, U.S. Army Corps of Engineers, National Weather Service, Kansas Water Office, other state and local government agencies) [FOC].

10. Send the preliminary Station Description to the Service Hydrologist at the National Weather Service Forecast Office responsible for the area of the gaging station [FOC].

11. Procure equipment for installation if necessary [FOC or designee].

12. Notify Kansas One-Call to mark underground utilities at least two full working days (but no more than two weeks) prior to installation. Calls to Kansas One-Call are made by dialing 811 [FOC or designee].

13. Responsibility lies on the FOC to make a final approval of the site design for the new installation and schedule staff to perform the installation.

\section{Field Install Processes}

1. Three reference marks are to be found or established, at least two of which must not be located on a bridge structure, and one reference mark should be located away from the flood zone whenever possible, while remaining within $1,000 \mathrm{ft}$ of the nearest reference mark.

2. Reference gage is installed.

3. Primary recording gage is installed, including the shelter, Data Collection Platform (DCP), power system, and everything else associated with the gage house.

4. Elevations for all reference marks and reference gages are determined by running station levels.

5. Datum of the gage relative to North American Vertical Datum of 1988 (NAVD 88) must be determined within 3 months of installing the gage by surveying from the nearest first order vertical control benchmark.

6. Channel cross section and bridge geometry should be determined, with elevations including flow over the road and flow into any overflow channels. This information is to be documented in the Station Description.

7. Bridge measuring section and wading measuring section should be cleared of vegetation and other debris that could affect measurements.

8. A discharge measurement should be made (for sites intended to have a discharge rating). 
9. Photos should be taken as described in the section of this document titled Photographs.

10. Begin transmitting data from the new site.

11. If the gage is part of a "gage move," the old gage must be removed, with close-out levels run.

12. Final inspection and approval of the completed installation is the responsibility of the Field Office Chief.

\section{Completing New Gage Installation}

Once a new gage has been installed and is transmitting, interested agencies must be informed and should be supplied with a station description and photographs of the gage site as necessary. Labeled photographs of the gage should be added to the site's NWISweb pages by the DBA. A site is considered to officially start on the day that collection of continuous stage data has begun. Stage data should be displayed to the public at this time in NWISweb, with discharge data displayed as soon as a working rating is developed. A preliminary stage-discharge rating is to be developed once at least three discharge measurements, one of which can be a gage height of zero flow (GZF), have been collected with a difference in stage between all of them of at least $0.5 \mathrm{ft}$. The rating is developed throughout the range in stage measured by the gage up to that point in time, with upper-end extension of no more than 2.5 times the highest directly measured discharge assuming that extension of the rating makes hydrologic sense based on observations of the controlling features of the stream, and extension on the lower end to one-fourth of the lowest directly measured discharge or to zero flow if the lowest measured discharge is 1 cubic foot per second $\left(\mathrm{ft}^{3} / \mathrm{s}\right)$ or lower or if a gage height of zero flow has been obtained with an accuracy of at least plus or minus $0.03 \mathrm{ft}$. Record work for the site begins once enough data is collected that can be considered of good quality yielding an accurate discharge rating throughout the range of stage recorded from the start of data collection.

\section{Measurement of Stage}

Many types of instruments are available for measuring the water level, or stage, at gaging stations. There are nonrecording gages (Sauer and Turnipseed, 2010, p. 13) and recording gages (Sauer and Turnipseed, 2010, p. 19). Because the various ways stage data may end up being used cannot be predicted, it is USGS Office of Surface Water (OSW) policy that surface-water stage records at stream sites be collected with instruments and procedures that provide sufficient accuracy to support computation of discharge from a stage-discharge relation, unless greater accuracy is required (Office of Surface Water memorandum 93.07).

In general, operation of gaging stations for the purpose of determining discharge includes the goal of collecting stage data at the accuracy of plus or minus 0.01 foot (Office of Surface Water memorandum 89.08). An explanation of USGS policy on stage-measurement accuracy as it relates to instrumentation is provided in Office of Surface Water memorandum 93.07, which states that instruments used to measure stage must be capable of sensing and recording stage with an accuracy of either $0.01 \mathrm{ft}$. or 0.2 percent of the effective stage being measured, whichever is less restrictive.

\section{Levels at Gaging Stations}

The various gages at a gaging station are set to register the elevation of a water surface above a selected level-reference surface called the gage datum. The gage's supporting structures — stilling wells, backings, shelters, bridges, orifice systems, and other structures - tend to settle or rise as a result of earth movement, static or dynamic loads, vibration, or battering by floodwaters and flood-borne ice or debris. Vertical movement of a structure makes the attached gages read too high or too low, and if the errors go undetected, it may lead to increased uncertainties or even errors in streamflow records. Leveling, a procedure by which surveying instruments are used to determine the differences in elevations between known reference marks, is used to set the gages and to check them periodically for vertical movement (Kenney, 2010, p. 1).

\section{Levels Frequency}

Levels are run at the frequency prescribed in Kenney (2010, p. 17). Specifically, new gaging stations are required to have levels run to determine stability in the established reference marks once every year for the first 3 years. After the stability of the reference marks has been established, levels should be run once every 3 years, unless the reference gage is located in the stream channel (such as a series of staff gages or reference points) in which case annual levels are required. Additionally the frequency may be extended to once every 5 years if the gaging station meets the criteria described in Kenney (2010, p. 18, table 5). If the levels frequency for a gaging station has been extended to once every 5 years, then documentation of that station's stability must be saved in a text file stored in that station's levels folder. If during any level run, regardless of the determined frequency of levels, the elevation of the primary reference gage differs from the gage datum by $0.015 \mathrm{ft}$. or more then levels must be run again the following year (Kenney 2010, p. 18). Gage datum zero should be tied to the North American Vertical Datum of 1988 (NAVD 88) by surveying from a first order control point to a stable benchmark at the gaging station. Leveling to a first order control point should be performed within the first 3 months of a newly established gaging station. Levels can be run as often as necessary if large or frequent corrections to the gages at a site cause suspicion in the performance of the reference gage. 


\section{Peg Tests of Leveling Instruments}

Kenney (2010, p. 6) requires that level instruments are kept in proper adjustment by performing a peg test within 7 days of a set of levels. The KSWSC has a more frequent requirement of a peg test before each levels run and a close out peg test following completion of the final levels run that week therefore ensuring that any levels run with an erroneous or questionable instrument are immediately recognized. Levels that have been run immediately prior to the failure of a peg test must be rerun with an instrument that is in proper calibration such that it successfully passes a peg test. An electronic directory showing the results of the peg tests is located at \ligskqdewgs002\KS_Data_Dir \KSWSC_general \Instrument_checks; available on request. The levels instruments are sent to the manufacturer or an authorized dealer for calibration and cleaning when it is apparent from peg tests that they are not working properly. Survey rod length between sections must be checked at the time of the peg tests with the results of the rod calibration check and rod serial numbers recorded in the notes field associated with the Instrument Information tab of the peg test routine using SVMobile. If a rod scale is determined to be outside of a tolerance of plus or minus $0.002 \mathrm{ft}$ the rod should be removed from service (Kenney, p. 10). Global Position System surveying instruments are calibrated as recommended by the manufacturer in the instrument manual.

\section{Levels Procedure}

Level procedures followed by USGS personnel pertaining to circuit closure, instrument reset, and repeated use of turning points are described in Kenney (2010) and in Office of Surface Water memorandum 11.05. As the results of running levels can have a significant impact on the established datum and perceived stability of benchmarks, levels should only be run in optimum weather conditions, when winds are light and the temperature is moderate, to prevent avoidable errors. To properly account for thermal expansion of the levelling rod, an infrared thermistor should be used to read the rod temperature prior to the first shot, and at any time when the rod temperature is suspected to be subject to change (for example, when moving from a shaded area to full sun on the rod, or if the air temperature is changing throughout the levels run) (Kenney, 2010, p. 12). When running levels for any reason, all benchmarks, reference marks, and gages must be included in the levels run, as well as a shot to the water surface and (whenever possible) bottom of wire weight when suspended near the water surface. Included in the field level form should be weather conditions, traffic conditions, instrument number, and the results of the post-run peg test. Self-leveling levels are used by the KSWSC. GPS surveying equipment are also sometimes used to survey from the gage reference marks to established first order vertical control benchmarks for the purpose of relating gage datum to the NAVD 88 . If a first order vertical control point is available within a quarter mile of, and requires less than 10 turning points (in one direction) from, a reference mark at the gage site, then a transit level should be used.

\section{Resetting Gages When Running Levels}

The primary recording gage should always be set to the water-surface elevation from levels when the levels indicate a difference between these two readings greater than $0.015 \mathrm{ft}$. Reference gages should be reset to the elevation determined by levels if they are in error by $0.015 \mathrm{ft}$ or more. Level notes must be completed using the current and approved levels computing software ("SV Mobile" for Windows as of May 2014). When gages are reset, field personnel document the reset by recording the changes on the field levels form. Any and all resets as a result of levels should be made on the day levels are run. If weather prevents an accurate reset to the gages, then the conditions are too poor to collect an accurate set of levels in the first place.

\section{Definition of Levels Responsibilities}

The level party chief is responsible for informing the assigned record worker that a levels run for the site has been completed. It is then assumed that responsibility for the levels data has been transferred to the record worker for the site, who is responsible for updating the Date of Last Levels and Reference Marks sections of SIMS, including addition, deletion, or movement of any surveyed points, prior to working the next record period, filling out the spreadsheet level-summary form, and archiving the electronic levels notes. These spreadsheets and notes are stored within a directory called "levels," which is contained in a subdirectory for each station, that subdirectory being located in the directory that is arranged by station in directory \igskqdewgs002\KS_Data_Dir\Station_Specific; available on request. Ensuring that levels are run correctly and that all level notes are completed correctly is the responsibility of the record reviewer for the site in question. All levels notes should be reviewed for accuracy, completion, and adherence to USGS and KSWSC policy during the review process for periods in which levels were run. Ensuring that levels are run at the appropriate frequency is the responsibility of the Field Office Chief.

\section{Instrumentation for Collection of Stage Data}

The type of instrumentation installed at any specific gage operated by the KSWSC is dependent on the types of data to be collected and the purpose of the gage. Types of primary recording gages operated by the KSWSC include float-type recorders, submersible pressure transducers (in stilling wells at lakes), nonsubmersible pressure transducers, noncontact radar stage sensors, submersible acoustic stage sensors, and creststage gages.

The responsibility for determining what type of waterlevel sensor is operated at each gaging station is held by the Data Chief in consultation with the Field Office Chief. Ensuring that equipment has been installed correctly is the responsibility of the Field Office Chief. Proper maintenance of gage instrumentation, or replacement if appropriate, is the responsibility of the personnel who service the gage. 
Accurate stage measurement requires not only accurate instrumentation, but also proper installation and continual monitoring of all system components to ensure the accuracy does not deteriorate with time (Office of Surface Water memorandum 93.07). To ensure that instruments record water levels that accurately represent the water levels of the body of water being investigated, primary recording and reference waterlevel readings are collected by independent means. Reference gages are nonrecording devices or reference points that can be used to manually obtain a measurement of the water surface elevation. Examples of these include wire weight gages, staff gages or reference points that the water surface elevation can be measured from. Primary recording gages are sensors that are interfaced with a data recorder and automatically provide a continuous record of stage. Examples of these include pressure transducers, radar or acoustic sensors, and float-pulley-encoder systems. Sometimes the primary recording and reference gages will each read accurate water surface elevations, but will not match each other because they are in different locations in the stream or lake. It is the responsibility of the personnel servicing the gage to note this condition and make modifications to the installation when appropriate.

Personnel servicing the gage are responsible for comparing primary recording and reference readings during each site visit to determine if the referenced water level is being represented correctly by all gages. Examples where this does not happen include when the reference gage is reading to a pool in a stream that has been cut off from the channel where the primary recording sensor is located, or if a stilling well has a well elevation that does not agree with a reference elevation outside of the well due to plugging or closure of the intake pipes. If a deficiency is identified, the personnel servicing the gage are responsible for thoroughly documenting the problem in the field notes, and either correcting the problem immediately or contacting the Field Office Chief so that corrective actions can be taken at the earliest opportunity.

\section{Operation of Reference Gages}

The most common reference gage used within the $\mathrm{KSWSC}$ is the type-A wire weight gage. This gage is set at the time that levels are run such that the reading from the wire weight gage agrees with the water surface elevation by levels. As a result, the wire weight gage reading at the checkbar can be compared directly to the checkbar elevation from levels. If there is a difference between the elevation of the checkbar and the wire weight reading at the checkbar of $0.020 \mathrm{ft}$ or greater then a linear correction equation must be developed with a magnitude of the difference between elevation of the checkbar and reading at the checkbar, and a magnitude of zero at the elevation of the water surface at which the wire weight gage was set.

The reading to which the checkbar is set should be written inside the wire weight box with a permanent marker (including the date it was last verified) so that each time the checkbar elevation is read with the wire weight, its accuracy can be verified. In the rare event that the checkbar elevation changes, as indicated by levels, the previous elevation should be crossed out and the new elevation and date written in the wire weight box. Any time that the gage is determined to read off at the checkbar by greater than plus or minus $0.015 \mathrm{ft}$, the gage must be reset to the last checkbar elevation as determined by levels with the previous reading and final reading recorded in the field notes. The checkbar elevation should be read with the wire weight and checked against the elevation determined during the last set of levels as part of every site visit.

If the stream is dry at the time of the levels run, or if it is difficult to obtain an accurate water-surface elevation with either the wire weight gage or the surveying equipment at the time, then the bottom of the brass weight of the wire weight gage can be shot directly by the level when the weight is lowered near the water surface. Wire weight gages approved for use in the KSWSC must be purchased from the USGS Hydrologic Instrumentation Facility (HIF).

\section{Staff Gages and Reference Points}

Staff gages and reference points are used in locations where the use of a wire weight gage is not possible because there is no bridge at the site, or where the wire weight gage is subject to frequent vandalism, or for concerns of safety. Staff gages are preferred over reference points as they provide a direct reading and are generally more stable. However, due to the higher costs associated with purchasing and installing staff gages, their use is restricted to sites where large debris is less likely to occur, which frequently destroys staff gages and reference points. Individual staff backing boards (with one or multiple sections of staff plates) must each have a reference point on them, which is used when running levels. This reference point is used to determine the elevation of the staff plates during a levels run. Additionally, a carpenter's level should be used to verify that plates are vertical when levels are run (Kenney, 2010, p. 27). If the gage is found to be out of vertical alignment, attempts should be made to reestablish vertical alignment, if vertical alignment cannot be reestablished the entire section of staff with the mount should be replaced. Reference point elevations determined during levels runs are used directly to measure elevation of the water surface.

\section{Applying Corrections to Reference Gages}

It is preferable to directly compare the actual elevation of the water surface with that read by the primary recording gage. The actual elevation of the water surface is considered to be the elevation determined by a corrected reference gage, as these instruments are generally more stable than the primary recording gage; therefore, in the field notes, the raw readings from reference gages should be recorded in the comment section for the gage in question with the correction that is applied. In the KSWSC, the only reference gages allowed to have corrections are wire weight gages. If staff gages are found to be reading off by more than $0.010 \mathrm{ft}$ or more, they must be moved into adjustment, or completely rebuilt if needed. If 
reference points are found to be off by $0.010 \mathrm{ft}$ or more, they must be assigned new elevations for use in gage readings. The correction for a wire weight gage should be noted as the linear equation applied to the gage. All corrected values should be recorded in the sensor readings field for the gage in question.

Below is an example of how wire weight gage corrections are noted in the electronic field notes:

\section{(a) 11:56 read 4.53 Corrected reading $=$ $1.0023 *$ (wwtRead)-0.0748 corrected value is 4.46}

\section{Operation of Crest Stage Gages}

Crest stage gages (CSGs) are installed at most continuous-record streamflow sites within the KSWSC coverage, as well as deployed at a small number of sites where peak stage is the primary data collected. The two types of CSGs used within the KSWSC are the traditional cork and stick CSG and the chalk CSG. These peak stage sensors should be checked on every visit for any peaks recorded and proper operation, and then re-corked or re-chalked as necessary with notes taken regarding the operating conditions of the gage. Intake holes should be checked for proper orientation to the flow, intake and vent holes should be inspected to ensure that they are not plugged.

\section{Operation of Primary Recording Gages}

Proper operation and maintenance of the primary recording gage is critical, as the gage height record provided by this instrument is the primary source for calculation of discharge using a stage-discharge rating. Readings from these instruments are automatically taken at standard intervals (generally 15 minutes, however some sites record in 5 minute, 30 minute or 60 minute intervals), and manually by hydrographers during site visits. The purpose of taking manual readings while on site is to compare the primary recording gages to the reference gage. By doing so, it can be determined if additional maintenance is needed on the primary recording gage, such as purging, cleaning, or uncovering an orifice end. Also it allows for determination of the need for any gage height corrections that adjust the primary recording gage to read within the allowable error of the reference gage reading.

\section{Allowable Error between Primary Recording Gage and Reference Gage}

The allowable error between the primary recording gage and reference gage is $0.015 \mathrm{ft}$. If the gages do not match within this allowable error, then the primary recording gage should be reset to the reference gage and a gage height correction be applied as necessary.

Exceptions to when the primary recording gage should be reset follow:

- If the reference gage is known to be reading in error, due to ice, damage to the instrument, or other issues
- If conditions do not permit a reading of the reference gage to within plus or minus $0.03 \mathrm{ft}$

- If the primary recording gage is subject to a variable stage gage height correction at the stage in question, and this correction brings the primary recording gage reading to within error

- If the stage is rapidly changing at a rate that does not allow accurate comparable readings of the primary recording gage and the reference gage before the stage has changed

- If the primary recording gage is a radar sensor that is subject to "radar dips" (fluctuations in measured stage below the true elevation due to waves on the water surface) at the time of the reading. Radar gages should only be reset at optimum conditions when no radar dips are present. This can be determined by observing the recent trend in recorded stages.

\section{Reading Primary Recording Gages}

The primary recording gages should be read to the hundredth of a foot. Some instruments provide readings beyond the hundredth of a foot, however these excessive place values are truncated by the data collection platform (not rounded), and are beyond the level of accuracy of any instruments used within the KSWSC. Therefore any digits provided to accuracy beyond the hundredth of a foot should be disregarded when making readings in the field.

Raw readings taken from the primary recording gage are entered into the sensor reading of SV Mobile for the relevant sensor. It is preferable to compare directly the readings obtained from the primary recording gage with the corrected values taken from the reference gage to verify and validate gage height corrections applied to the primary recording gage. Any gage height corrections applied to the primary recording gage should be mentioned in the comment field for that primary recording gage. The comment describing gage height corrections should state the magnitude of correction, and, if necessary, the equation from which the correction was derived.

\section{Operation of Non-Submersible Pressure Transducers}

Non-submersible pressure transducers are the most common type of instrument used as primary recording gages in the KSWSC. These instruments typically show the last gage height reading obtained on their routine measurement schedule when the display is first turned on. It is necessary to force the instrument to take a new reading when inspecting the gage.

Non-submersible pressure transducer requires an orifice to be submerged in the stream. Proper operation of the instrument can be interrupted by conditions that the orifice is subject to in the stream. Things affecting the orifice that can prevent a non-submersible transducer from accurately measuring the correct stage include: 
- Movement of the orifice by debris or ice in the stream

- Partial clogging of the orifice end by algal growth, calcification, or debris

- Draw down of the orifice because of the Venturi effect

- Draw down of orifices installed on the downstream side of bridge piers or other objects

- Covering of the orifice by sediment or other material

- Freezing of the orifice end or freezing resulting in constriction of the gas line between the orifice and the pressure transducer

- Ice cover in the stream increasing the water pressure under the ice

- High suspended-sediment concentrations increasing the density of the water, which, in turn, increases the head pressure at the orifice (about 0.1 percent increase for every 1.0 gram of sediment per liter of water)

Before resetting the primary recording gage, it is necessary to try to determine the cause of the difference between it and the reference gage to know if a correction should be applied, and if so, how to properly account for timing and potential vertical variability of the correction. If the orifice is reachable, then the hydrographer should inspect the orifice and pipe leading to the orifice ensuring that it is securely mounted with no movement, that the orifice end is not covered with sediment or other material, and that the orifice end is not subject to partial clogging. The gas line should be purged prior to resetting the gage to force any moisture or debris from the gas line.

Drawdown situations should be avoided to the greatest extent possible. For sites where high water velocity is possible in the vicinity of the orifice end, a static tube orifice should be used to prevent draw down due to the Venturi effect. Sites that are subject to the draw down use variable stage gage height corrections to account for this problem. The methods described to develop variable stage gage height corrections are in the Variable Stage Gage Height Corrections section. Nonsubmersible pressure transducers should not be reset to the reference gage when it is suspected that the non-submersible pressure transducer is affected by draw down, or increased pressure due to ice cover or high suspended-sediment concentrations.

Non-submersible pressure transducers have a "bubble rate" (air-flow rate) at which the air in the orifice line is supposed to produce bubbles at the orifice end in the water. This bubble rate is generally programmable within the pressure transducer system; however bubble rates in the stream almost never match exactly with that set in the system. The rate at which bubbles appear in the stream can indicate improper function of the system (there generally should be at least one bubble every 4 seconds or so). Therefore, the bubble rate should be checked in the stream periodically, and at any time that the gage requires reset. Bubble rates in the non-submersible pressure transducer system should be set to at least 60 bubbles per minute. At stations that have more than $200 \mathrm{ft}$ of gas line between the orifice end and the pressure transducer, the bubble rate should be set to the highest rate possible.

\section{Operation of Radar Stage Sensors}

Radar stage sensors are less expensive and are easier to install and maintain than the other types of primary recording gage sensors, but they also have limitations that can reduce their accuracy or even render them inoperable in certain conditions. These instruments must be above the water surface to operate, so if they become submerged (for example when the bridge they are mounted to is inundated), they will cease to operate; so care must be taken to only install them at locations where they will never become inundated. They are calibrated to measure a water surface and will give erroneous readings when the surface below them is ice, snow, the streambed, or any surface other than water. This makes them unsuitable for sites where the stream can become very narrow, or where ice can form below the bridge while the control remains ice free. Wind-driven waves on the surface of the water occasionally cause these instruments to sense readings that are biased low, called "radar dips." These low-biased values must be edited as described in the Gage Height Record section of this document. Because these instruments generally take a long time to make manually-forced readings on site, and because these readings are occasionally affected by radar dips requiring editing to correct for low bias, it is acceptable to use radar stage sensors readings from the continuous record in NWIS for comparison with the reference gage at all times except when the radar sensor gage requires a stage value reset.

\section{Operation of Submersible Pressure Transducers}

Submersible pressure transducers are less expensive and easier to maintain that non-submersible transducers, but can be damaged if frozen, so in Kansas they are generally used only at lakes in stilling wells. All submersible pressure transducers used within the KSWSC coverage area must be vented to the atmosphere. Non-vented submersible pressure transducers require compensation for changes in atmospheric pressure, and therefore are not to be used for data collection activities. These pressure transducers report gage height based on the hydrostatic pressure exerted on the submerged transducer, therefore it is critical that they be mounted in such a manner that the transducer is immobile to provide accurate and consistent readings.

\section{Verification of Peak Stage}

Between site visits, when direct comparison between the reference and primary recording gages cannot be made, CSGs and high water marks (HWMs) serve as a surrogate reference gage for which peak data can be used for comparison with the primary recording gage. Peaks recorded by CSGs and HWMs 
can record a peak in between the sampling interval of the primary recording gage and indicate if a primary recording gage was not working properly during the peak (such as a pressure transducer being subject to drawdown during high flow or determining if an orifice was moved prior to or following the peak), as well as allow for better estimation of missing data when the primary recording gage fails during a hydrologic event. All independent peaks determined at a site are recorded in the field forms in the High Water Mark Measurement section with an explanation of how the mark was obtained, and an estimated plus or minus accuracy in feet. A section of the station analysis is reserved for comparison of the recorded peak stage and the independent measurement's peak stage. In accordance with Office of Surface Water Technical Memorandum 2014.06, the annual peak stage should be described in the station analysis, which ends the respective water year in which the peak occurred. This description of the annual peak stage must include the method by which the peak stage of the year was verified to be true and accurate. If the independent peak stage value does not verify the recorded peak stage within $0.05 \mathrm{ft}$. (with consideration for the determined accuracy of the independent peak), then the independent peak stage should be input into the data-corrected-gage height record by the methods described in the memorandum.

\section{Site Visits}

Periodic visits to gaging sites are necessary to perform routine inspections and maintenance of the gaging equipment as well as to inspect the conditions of the stream and make direct measurements of discharge. It is KSWSC policy that gages with continuous records of discharge be visited and measured at least once every 56 days ( 8 weeks), or more frequently as necessary based on hydrologic and other conditions. All other gages are to be inspected at least once every 90 days.

There are several procedures that must occur during every site visit. These procedures are to ensure the safety of the field person, as well as the integrity of the data collected. First of all, strict adherence must be made to the site-specific traffic control plan for each site, as outlined in the KSWSC Traffic Control Plan (Marintzer and Foster, 2014) and the Job Hazard Analysis for site in question. During every site visit, the reference gage and primary stage sensor should be read. At all sites at which a discharge is computed, the control condition should be noted with a picture taken of the control, unless the control is hard to reach and no shift is indicated by the measurement or suspected based on comparison of discharge to index sites, in which case inspection of the control can be foregone entirely. If a site has equipment to sense water temperature (including in situ hydroacoustic instruments) or air temperature, then an independent comparison temperature should be acquired at each visit.

\section{Discharge Measurements}

Numerous methods and procedures are used to measure stream discharge by the KSWSC. It is the responsibility of the hydrographer in the field to recognize and use the method that will result in the highest quality and most efficient measurement, given the conditions at the time of the measurement. In the KSWSC, most low flow measurements are made by a hydrographer wading in the stream using an acoustic Doppler velocimeter (ADV), and most high-flow measurements are made by deploying an acoustic Doppler current profiler (ADCP) from a manned boat or tethered from a bridge or cableway. For cases of extreme low flow, when use of an $\mathrm{ADV}$ is determined to be impractical or inaccurate, measurements are made using a Parshal Flume or volumetric methods. Mechanical current meters are generally only used at times when an acoustic instrument is unavailable or fails to work due to conditions in the stream such as very high suspendedsediment concentrations.

\section{Measurement Frequency}

Direct measurements of discharge are necessary to maintain an accurate and current stage-discharge rating for the gaging site. It is KSWSC policy that gages with continuous records of discharge be measured at least once every 56 days (8 weeks), or more frequently as necessary based on hydrologic and other conditions. Discharge measurements must be made at varying stages and on a routine basis to establish a stage-discharge rating and define the timing and magnitude of variations to that rating. The hydrographer responsible for the site must decide when unscheduled measurements are needed by using the go 2 program, knowledge about the site and these uses of its data, and input from the Field Office Chief. Attempts are made to measure at or near the peak maximum and minimum flows of the year when possible.

The presence of ice in the stream often results in unstable control conditions, even with otherwise steady flow. As a result of the unstable control conditions, the interval between measurements for a site known to be affected by ice is decreased to no more than 21 days. Ice forming on the control results in a variable and usually uncertain stage-discharge relation, requiring the discharge to be estimated. This more frequent measuring schedule allows for increased accuracy in estimations for sites that have ice on the control.

\section{General Procedures for Making Discharge Measurements}

For all measurements of discharge, readings of the primary and reference gages are required both before and after the measurement. These readings should be taken as close to the start and end times of the measurement as possible to achieve the most accurate representation of stage for the measurement. The stage associated with a measurement 
should be based on the reference gage. If at the time of the discharge measurement it is determined that the reference gage is not working or is otherwise unavailable, an attempt should be made to establish a temporary reference point from which the elevation can be reconciled by levels as soon as possible. Exceptions to this rule only exist when the reference gage does not accurately represent the stage for that site, for example if the reference gage is reading to ice or to a water surface not representative of the gaged water surface. If the reference gage is reading to a water surface not representative of the gaged water surface, then a temporary reference point should be established in the gaging pool with a permanent reference established and levels run to all reference points as soon as possible.

A weighted mean gage height must be used to determine the stage associated with a discharge measurement if, during the time of the measurement, the elevation of the stream is subject to a net change greater than $0.10 \mathrm{ft}$ (Turnipseed and Sauer, 2010, p. 39). Calculations should be performed using the spreadsheet available in the BARC computer program with results saved for archival with the discharge measurement.

An independent water temperature measurement must be made and documented prior to every measurement made with hydroacoustic instruments, or during each visit to a site with an in situ hydroacoustic instrument such as an acoustic Doppler velocity meter (ADVM) (OSW Technical Memorandum 2010.07). The water temperature measured by the hydroacoustic instrument should be within 2 degrees Celsius $\left({ }^{\circ} \mathrm{C}\right)$ of the independent water temperature measurement, otherwise the instrument should not be used to make the measurement and should be returned for repair. The independent water temperature must be measured directly next to the hydroacoustic instrument, which requires special instruments or extra effort for the in situ instruments.

\section{Check Measurements}

Following completion of a streamflow measurement at a site with a discharge rating, the discharge measured should be compared with the current discharge data displayed on NWISweb using a mobile device to determine if a check measurement is necessary. A check measurement should be made when the original measurement is suspected of having problems, or if a measurement does not plot within the allowable error $(5$ percent for a measurement rated good, 8 percent for a measurement rated as fair, and 13 percent for a measurement rated as poor) plus 5 percent, or $0.10 \mathrm{ft}^{3} / \mathrm{s}$ (whichever is greater) of the shifted-rating curve in use. If there is an obvious and explainable reason for the shift, and the measured flow seems reasonable and accurate, then simply explain the reason for the change in shift that is exempting the check measurement, and then a check measurement is not required. For instance, there may be an obvious change of the control that would explain the deviation. All such explanations should be clearly documented in the measurement notes. If a satisfactory explanation cannot be found then a check measurement must be made.

Check measurements are performed by changing as much about the measurement as practically possible while making the measurement at as close to the same time and gage height as the original measurement.

\section{Hierarchy for Things to Change When Making a Check Measurement of an ADCP Measurement:}

- If the stream can be waded, make a wading midsection measurement with an ADV or mechanical current meter

- If the stream cannot be waded, switch (as much as is possible) to a different measurement cross section

- If no other quality cross sections are available without diminishing the accuracy of the measurement due to inflow/outflow or changing stage, change to a different ADCP instrument

- If no other ADCP instrument is available, change the instrument set up (water mode, bottom mode, and so on) as much as possible, while maintaining practical settings for the conditions at hand

- If more than one person is on site, switch who operates the computer and who operates the boat

- If none of the aforementioned options are practical, a midsection measurement with a current meter should be made

- If a current meter is not available, a midsection measurement with the ADCP should be made

\section{Hierarchy for Making a Check Measurement of a Midsection ADV Measurement:}

- Check the instrument initially used for errors in the $\mathrm{QA} / \mathrm{QC}$ test. If the instrument does have errors in the $\mathrm{QA} / \mathrm{QC}$ test, or if the temperature is obviously reported erroneously for some verticals, then all considerations for check measurements should avoid the continued use of the instrument in question.

- When practical, based on conditions of the stream, change measurement method (for example, change to a current meter, moving boat ADCP, flume, volumetric measurement, and so on). Due to stream conditions, available cross sections, and available instruments a different measurement method may not be possible.

- Most measurements are made using the best available cross section first. The next best available cross section should be used if a check measurement is necessary, however if this results in greatly reduced measurement 
quality due to no other quality cross sections available then the check measurement may be made in the vicinity of the original cross section. When remaining in the vicinity of the original cross section, the tagline should be restrung in a new location upstream or downstream, the hydrographer should traverse the stream from the opposite direction to the original measurement, and the width and locations of the partial sections should not be identical to the original measurement. It is always preferable to find a new measurement location if by doing so a suitable cross section can be used.

- If possible, change personnel operating the ADV and the tagline used.

\section{Making A Check Measurement of a Midsection Current Meter Measurement:}

The methods for making a check measurement for a current meter measurement are similar to those used for an ADV measurement. It is preferable to change instruments to an ADV or ADCP. If that is not possible and no other current meter is available, then the current meter should be subject to an additional spin test and thorough inspection of the instrument prior to performing the check measurement.

\section{Midsection Measurements of Discharge}

Most midsection measurements made within the KSWSC are made using the Flowtracker ADV; however Pygmy and Price AA mechanical current meters, as well as ADCPs are occasionally used to make midsection measurements. Methods for collecting measurements using these instruments are generally very similar, with variance predominately in the working limitations of the various instruments. Quality control procedures require special consideration for the different types of instruments.

\section{Quality Control Tests For ADVs}

The Flowtracker ADV has a built-in quality control (QC) test, which is to be performed in the flowing part of the stream, away from any obstructions, prior to each discharge measurement. The results of this QC test are stored internally in the Flowtracker along with the associated measurement files. Upon returning to the office, the measurement files should be downloaded and stored in the digital archive as described in the section titled File Folders for Surface Water Stations, therefore resulting in archival of the attached QC test result.

Due to the dependence of the acoustic instrument on accurately reading the water temperature, an independent water temperature should be read by placing a thermometer in the vicinity of the ADV head and obtaining a comparison water temperature reading. If the comparison water temperature reading is not within $2{ }^{\circ} \mathrm{C}$ then the measurement should not be performed using the instrument (Office of Surface Water memorandum 2010.07).

All ADVs in the KSWSC are enrolled in a program through which the HIF performs tests on the instruments at 3 year intervals. During the testing procedure, the instrument is subject to tow-tank testing, testing of the thermistor, and a beam check is performed. The results from these tests are maintained by the KSWSC Hydroacoustics Specialist, and can be found (organized by instrument) in the KSWSC digital archive at the internal network location \igskqdewgs002\KS_Data_Dir \KSWSC_general \Instrument_checks $\backslash$ Flowtrackers.

\section{Quality Control Tests for Mechanical Current Meters}

A timed spin test must be made under controlled conditions within the 24 hours preceding a measurement, when the results of the meter are suspect, and before and after repairs. To perform the spin test the meter must be placed in a level and stable state, in an environment where no wind currents or drafts could affect the results of the spin test. Sharply spin the rotor while starting a stopwatch. Stop the stopwatch when the rotor comes to a complete stop. The minimum, acceptable spin time for pygmy meters is 0:45 seconds, and for AA meters is 2:00 minutes (Turnipseed and Sauer, 2010, p. 51). If the meter fails, the meter should be inspected, cleaned, and adjusted before being tested again. Meters that continue to fail the spin test must be sent off for repair before being returned to service.

All spin tests should be documented in a spreadsheet titled "Current_Meter_Spin_Tests.xlsx" with the date and duration of the spin test, as well as the initials of the person performing the test. This EXCEL file is can be found in the directory at \ligskqdewgs002\KS_Data_Dir \KSWSC_general $\backslash$ Instrument_checks $\backslash$ Price Meters available on request.

\section{General Rules for Midsection Discharge Measurements}

Methods and rules for making midsection measurements of discharge are described in Turnipseed and Sauer (2010). The width of the stream and width between verticals should be measured directly using a graduated tagline or tape measure, which is strung perpendicular to the mean direction of flow for wading measurements. For bridge measurements graduated marks on the bridge rail are used to determine widths, and for cableway measurements graduated marks on the cable are used. When measuring using an ADV, flow angles are determined by the instrument. To calculate an accurate velocity corrected for flow angle, the ADV wading rod must be aligned perpendicular to the tagline. Flow angles for mechanical current meter measurements must be determined by the hydrographer as described in Turnipseed and Sauer (2010, p. 25).

It is desirable to keep section discharge per vertical less than 5 percent of the overall measured discharge of the stream to provide accurate data in an efficient manner. This goal is best accomplished by targeting for 25 verticals to be measured at locations of near equal discharge per discharge 
measurement. The minimum allowable distance between verticals is $0.3 \mathrm{ft}$. During low flow conditions or in very narrow streams it may not always be possible to achieve 25 verticals in the highest quality measuring sections. It is preferable to use a measuring section that has a more uniform horizontal velocity profile with an even bottom rather than a measuring section that allows for 25 verticals to traverse the stream. A measurement made in a location as such is prone to have midsections that contain more than 5 percent of the total measured discharge.

\section{Duration of Velocity Measurements}

Samples of velocity should be of duration of 40 seconds, per measurement point, per vertical. In circumstances where the stage is changing rapidly, or when a longer duration may present a hazard to the hydrographer, the sample time can be decreased to 20 seconds. If the duration of velocity sampling is reduced then the quality rating of the measurement should be reduced as a result with the reason for using a shorter sampling duration clearly stated in the field notes.

\section{Minimum Depth for Midsection Discharge Measurements}

The minimum total depth at a vertical for obtaining an accurate measurement of velocity using the Flowtracker ADV, pygmy meter, or Price AA meter is $0.3 \mathrm{ft}$. Although the Flowtracker will continue to work as low as $0.2 \mathrm{ft}$, velocity measurements in depths of less than $0.3 \mathrm{ft}$ are prone to spikes in data and therefore are of diminished quality and should not be made; therefore midsection discharge measurements using these instruments should only be attempted if all verticals to be used in the measurement have a depth of at least $0.3 \mathrm{ft}$.

\section{Measurement Depths at a Given Vertical}

When using the Flowtracker ADV or pygmy meter, velocity measurements should normally be taken at 0.6 of the depth below the water surface in the vertical when the water depth at the location is between 0.3 and $1.50 \mathrm{ft}$, and this is then used as the mean velocity in the vertical. Velocity measurements should be made at depths below the surface of both 0.2 and 0.8 of the total depth of the vertical (and those velocities averaged together) for total vertical depths greater than $1.50 \mathrm{ft}$.

The Price AA meter is more susceptible to errors introduced by the top of the water column; therefore the velocity is measured at 0.6 of the depth below the water surface in the vertical where the water depth at the location is between 0.3 and $2.50 \mathrm{ft}$, and this is then used as the mean velocity in the vertical. Verticals with a total depth of greater than $2.50 \mathrm{ft}$ must be measured at depths below the surface of both 0.2 and $0.8 \mathrm{ft}$ of the total depth of the vertical (and those velocities averaged together) when using the Price AA meter.

Exceptions to these rules include the following:

- If something interferes with the measurement at the 0.2 or 0.8 depth (such as aquatic plants on the streambed, or slush ice near the surface), the 0.6 depth can be used as the point to measure a single mean velocity (the measurement quality rating should probably be downgraded).

- If the velocity measurement at the 0.2 depth is not faster than the velocity at the 0.8 depth, then the vertical has a nonstandard velocity profile. In this case, a third velocity measurement should be taken at the 0.6 depth, and then that 0.6 depth velocity averaged with the average of the velocities 0.2 and 0.8 depths for the mean depth of the vertical.

- If the flow is rapidly changing, or conditions are unsafe (but not so unsafe as to completely stop the measurement), a 0.6 depth velocity can be used as the mean instead of an otherwise required average of the 0.2 and 0.8 depth velocities to speed up the measurement. Note that this would be used in conjunction with reducing the individual point measurements from a minimum of 40 seconds down to 20 seconds. Further note that it is preferable to just reduce the measurement time, and not reduce number of points within a vertical that velocities are measured.

\section{Rating of Midsection Discharge Measurements}

It is the responsibility of the hydrographer in the field to rate the quality of the measurement, taking into account several aspects that are both numerically based and observationally based. The aspects that are numerically based are recorded in the output from the Flowtracker as statistical uncertainty (referred to as STATS in the Flowtracker program) (FlowTracker Technical Manual, March 2009, p. 104) and the percent of total measured discharge per midsection. The base level rating of the midsection measurement determined numerically is listed in the following table. Note that if a measurement exceeds any of the "Fair" rating criteria, it should be rated Poor.

\begin{tabular}{cccc}
\hline $\begin{array}{c}\text { Best possible rating } \\
\text { of the midsection } \\
\text { measurement }\end{array}$ & $\begin{array}{c}\text { Maximum percentage of } \\
\text { total flow recorded in } \\
\mathbf{8 0} \text { percent of midsections }\end{array}$ & $\begin{array}{c}\text { Maximum percentage } \\
\text { of total flow found in all } \\
\text { midsections }\end{array}$ & $\begin{array}{c}\text { Maximum percentage of } \\
\text { statistical uncertainty }\end{array}$ \\
\hline Excellent & 1.5 & 2 & 1.5 \\
Good & 5 & 8 & 3.5 \\
Fair & 8 & 12 & 7 \\
\hline
\end{tabular}


In addition to the base level of uncertainty determined numerically, the hydrographer should take into account visual observations that can only work to decrease the overall uncertainty of the measurement. These visual observations include the following: quality of the measuring section, accuracy of width and depth measurements, if the tagline was strung perpendicular to the mean flow, if the ADV wading rod was held at true perpendicular to the tagline, if the tagline was experiencing stretch or sag, and if the proper stance was performed while making the measurement (downstream and to the opposite side of the wading rod from the sampling volume).

\section{Midsection Measurements from Ice Cover}

The highest priority in collecting streamflow data during winter periods (or at any time) is employee safety. Job hazard analyses for individual sites will describe conditions that require multiple-member crews on site, and when personal floatation devices are required.

The KSWSC discourages measurement of discharge on ice-covered streams where slush ice is present and does not stock current meters approved for these conditions. Kansas Water Science Center policy on the use of metering equipment in ice-covered streams where no slush ice is present is that type AA meters with conventional metal-bucket rotors, ADVs or ADCPs are acceptable for use in slush-free conditions. When the effective depth of water under ice cover is less than 0.5 foot, a pygmy meter or ADV must be used.

\section{Midsection Methods for Measurements under Ice Cover}

Measurements of discharge under ice cover differ from standard midsection measurements in that the vertical velocity profile is nonstandard, and that the depth of the water as measured in a hole in the ice is not representative to the area over which water is flowing; therefore, an effective depth and velocity coefficient must be used in the calculation of discharge. This effective depth is the result of the total depth of water minus the distance from the water surface to the bottom of the ice (Turnipseed and Sauer, 2010. p. 29). Ice depth should be measured using an ice stick, which is a stick (graduated in units of 0.01 or $0.10 \mathrm{ft}$ ) with an L-shaped piece on the bottom used to hold the bottom of the stick on the bottom of the ice. When the flowing water is in contact with the bottom of the ice, the ice serves as a friction force on the flow, and reduces the velocity at the top of the water column, therefore creating a nonstandard vertical velocity profile. Because of this, if the 1-point velocity method is used (measured at 0.6 depth), a 0.92 coefficient must be applied to it to obtain the mean velocity in the vertical. If 2-point ( 0.2 and 0.8 depths) or 3-point (0.2, 0.6 and 0.8 depth) velocities are obtained then the normal mean velocity computations still apply (Turnipseed and Sauer, 2010, p. 29). All other methods are similar to those of a standard midsection discharge measurement. It is acceptable to have more than 5 percent of the overall discharge in a partial section; however a minimum of 15 partial sections should be used. All attempts should be made to keep partial section discharge less than 10 percent of the total discharge (Turnipseed and Sauer, 2010, p. 29). A much more detailed explanation of how to make discharge measurements under ice cover are described on pages 29-31 of USGS Techniques and Methods 3-A8 (Turnipseed and Sauer, 2010).

ADCPs may also be used to make measurements of discharge under ice cover, though this is rarely done by the KSWSC. Procedures for doing this are described in "Standard Operating Procedures for under-ice discharge measurements using ADCPs, Paul Campbell, Water Survey of Canada, 2014." (Campbell, 2014)

\section{Midsection Measurement Using an ADCP}

Midsection measurements using ADCPs are made where a moving boat ADCP measurement cannot be made or as a check measurement to a moving boat ADCP measurement. Cases where an ADCP may work for a midsection measurement, but not for a moving boat measurement, include channels with vegetation on the bed, streams with excessively high suspended-sediment loads, and streams with a large amount of moving bed. The procedures for using the midsection method with an ADCP are similar to the ones used with mechanical meters; however, instead of point measurements of velocity, the average velocity is obtained from profiling the velocity in nearly the entire water column at each section (Turnipseed and Sauer, 2010). Width of subsections is directly measured by the hydrographer using graduated bridge marks, a tagline, or laser range finder. Depth and velocity measurements are made directly by the ADCP, with hydrographers manually measuring flow angles. As with other midsection measurements, 25 subsections are necessary to make an accurate measurement. When making a midsection measurement using an ADCP, it is KSWSC policy that the latest vendor supplied midsection software, with a status of recommended or approved by the Hydroacoustics Work Group, must be used. Using the software designed for making a standard moving boat ADCP measurement is not allowed.

\section{Moving Boat Measurement Using an ADCP}

\section{Instrument Testing and Quality Control}

Acoustic Doppler Current Profilers are tested by the HIF every three years in accordance with Office of Surface Water Technical Memorandum 2014.04. Additionally, all ADCPs within the KSWSC are gathered for a test consisting of comparison measurements once every other year. Newly purchased instruments should be subject to comparison measurements to a known reliable instrument throughout the range of potential conditions before being put into service. The results from these tests are maintained by the KSWSC Hydroacoustics Specialist, and can be found in the KSWSC digital archive at |ligskqdewgs002\KS_Data_Dir|KSWSC_generalIInstrument_ Checks $\backslash A D C P s \backslash$; available on request. 


\section{Collecting Data}

Methods, procedures and policies for operating, maintaining, and reviewing the data collected by ADCPs are described in "Measuring Discharge with Acoustic Doppler Current Profilers from a Moving Boat, Mueller and others (2013)." Described in the following 10 sections are areas of extra importance, or topics ADCP users frequently have questions about.

\section{Measurement Duration}

Moving boat measurements of discharge under steady flow conditions are to be of a minimum duration of $720 \mathrm{sec}-$ onds (12 minutes) of exposure time (OSW Technical Memorandum 2011.08). Exposure time is the total amount of time during which transect data is actively collected. Not included in exposure time is the amount of time to collect moving bed tests, run instrument self-checks, read gages, or time in between transects. When measuring rapidly-changing flows, it is acceptable to have a duration of less than 720 seconds, however the rating of the measurement should be downgraded accordingly, and measurements should always consist of reciprocal pairs of transects starting on each bank.

\section{Unmeasured Areas of Discharge}

ADCPs have minimum depth requirements that prevent them from measuring the flow all the way to the edge of the stream; therefore flows near the edge must be estimated. This estimation is performed automatically by the data collection software based on a sample of the velocity at the edge of the measurable portion of the stream and the assumed shape of the channel bed from the sampling location to the bank. If a single estimated-edge discharge contains more than 5 percent of the overall discharge, an alternate method of measuring/ estimating the discharge (other than the standard method in the ADCP software) should be used to check the edge discharge computed by the ADCP software.

\section{Multiple Channel Considerations}

Multiple channel discharge measurements are undesirable due to the increased unmeasurable areas. However, it is not always possible to avoid making measurements in such locations. When measuring in multiple channels, the total exposure time is counted as the total amount of time spent performing transects in all of the channels. It is necessary to perform a moving bed test in each of the channels unless the discharge in a channel is less than 10 percent of the overall discharge. It is necessary to include notes assigning moving bed tests and transect data to the appropriate stream channel.

\section{Moving Bed Tests and Corrections}

It is required that a moving bed test be performed for every moving-boat discharge measurement obtained using an ADCP. In the KSWSC there are three types of moving bed tests used: the loop method, the single-point stationary method, and the multiple-point stationary method. Each is the preferred method for different specific conditions.

It is recommended that if KSWSC hydrographers strongly suspect that the ADCP will not find any moving bed in the stream, that they perform a single-point stationary moving bed test (procedures outlined in Mueller and others, 2013 , p. 53-54). The reasons for using a single-point stationary method are that this method works with all ADCPs, does not require a compass calibration (which can be time consuming and difficult to adequately do at some sites), and generally takes less time than the other two methods.

If it is suspected that the ADCP will find moving bed in the stream, or if the single-point stationary test originally run found a moving bed, then one of the two other methods must be used to the measure the magnitude of moving bed across the channel so that the discharge data can be corrected for the negative bias that moving bed introduces into it. The preferred method for correcting discharge because of moving bed conditions is the loop method (procedures outlined in Mueller and others, 2013, p. 55-56). This method is preferred over the single or multiple-point stationary bed tests for correcting the discharge because it is based on a more spatially comprehensive assessment of the moving bed. This method requires that the ADCP have an internal compass accurately calibrated as close as possible to the measuring section at the site before the loop test begins; and requires that very little bottom-tracking data be invalid during the test. Loop tests should be made of a duration exceeding 3 minutes of exposure time, with a boat speed that is the lesser of a boat speed that requires no less than 3 minutes to complete the loop path or a boat speed that is less than 1.5 times the mean water speed. If the mean water speed throughout the traversed section of the stream is less than $0.8 \mathrm{ft} / \mathrm{s}$ then the loop test is not considered a valid method to correct for moving bed.

If the site has moving bed and the ADCP does not have a compass (such as some StreamPro models), or the compass cannot be calibrated properly, then a moving bed test using the multiple-point stationary method should be made and used to correct the discharge if needed. The multiple-point stationary method is essentially the same as the single-point method described above, but with more sample points (Mueller and others, 2013, p. 53-54). The same is true if more than 10 percent of the ensembles consistently have invalid bottom-track data in loop tests during a measurement.

Moving bed corrections indicated by the software that will result in a change to the overall discharge of greater than 1 percent must be applied. Measurements with moving bed tests indicating a correction of less than or equal to 1 percent should not have a correction applied.

It is the responsibility of the hydrographer in the field to recognize situations likely to result in the need to apply a moving bed correction, and start with the most appropriate method of testing for moving bed; and then make any additional moving bed tests and correct the data appropriately as needed. 
Items of note in the KSWSC policy on moving bed tests:

- Moving bed tests should be made before discharge transects are collected.

- Single-point stationary moving bed tests must be recorded for at least 5 minutes (300 seconds), with the ADCP at the location in the measurement section expected to have the highest potential for a moving bed.

- Multiple-point stationary moving bed tests must consist of measurements of moving bed in at least 3 locations in the measurement section, including the location in the measurement section expected to have the highest potential for a moving bed. Data must be recorded at each of these 3 plus locations for a minimum of 3 minutes at each location (written communication from Dave Mueller in Surface Water Technical Review of the Kansas Water Science Center August 26, 2011)

- If the ADCP boat is not anchored or tied off to a stationary object, the minimum times above for recording stationary tests must be doubled.

- If the compass cannot be calibrated with a resultant error of less than 3 degrees after three attempts, or if the percentage of invalid bottom-track data during a loop test always exceeds more than 10 percent after three attempts, then the multiple-point stationary test should be used in place of the loop test to measure the moving bed and correct the discharge transects.

\section{Use of Collected Transect Data}

All transects collected must be averaged together as the total discharge for the measurement. It is allowable to discard transect data only under the circumstance of obviously erroneous data. The reasoning for discarding any transects must be clearly described in the measurement notes with an explanation stating what the error in the data is. Example circumstances that may result in transects not being used include excessive amounts of missing or erroneous data, incorrect instrument settings that cannot be changed in post-processing, or a path of the instrument across the channel that substantially reduced the quality of the measurement. Even when transects are not used, measurements should always consist of reciprocal pairs of transects starting on each bank, so additional transects must be made if possible, or extra transects deleted if needed to meet this requirement.

\section{Processing ADCP Measurements}

After data collection has been completed, corrections to the data are made by applying corrections for moving bed, adjustment to the extrapolation method, and screening erroneous data through application of thresholds or discarding erroneous transects. Each of these processing procedures should be described in the processing notes for the measurement. At a minimum, processing notes will contain mention of the moving bed test results and examination of the extrapolation method. If further processing is required additional notes must describe changes to the raw data. If moving bed test results indicate that a correction should be applied, the original discharge is noted, as well as the corrected discharge. If EXTRAP indicates that the extrapolation method should be changed, the new method being used must be reported in the notes, as well as the percent change to discharge.

\section{Application of Extrapolation Methods}

The extrapolation method used to calculate discharge in unmeasured portions of the column of water using an ADCP can have a substantial effect on the total discharge calculated for that measurement. To most accurately determine the proper extrapolation method the program EXTRAP should be used as a guide to analyze the data. Care should be taken when applying recommended changes to the extrapolation method that these recommendations make sense hydraulically given the bed and channel conditions, wind driven effects, and flow regime of the measuring site at the time of the measurement. If the change recommended by EXTRAP has a difference in total discharge listed in the sensitivity analysis of greater than 1 percent, and the hydrographer determines that the recommended change is hydraulically sound given the conditions, then the hydrographer must apply the recommended changes in the WinRiver software. It is possible for EXTRAP to recommend an extrapolation coefficient greater than that allowed by the WinRiver software (currently 0.50 ). If applying a coefficient greater than that allowed by the software is necessary, then the hydrographer should use the percent difference for the recommended change and apply that percent change to the overall discharge with no change to the extrapolation methods applied within WinRiver. Users should be aware that an application such as this is outside the design plans of the EXTRAP program, as the sensitivity analysis does not take into account the unmeasured areas of edge discharges, however this application in many cases will result in a discharge closer to that indicated by the change to extrapolation methods than simply using the largest coefficient allowed by the WinRiver software.

\section{Field Processing of Measurements}

In adherence to OSW Technical Memorandum 2012.01, all ADCP measurements must be processed on site following completion of data collection. Processing of measurements on site is an important step in determining if a check measurement is necessary based on the data collected. Additionally it is KSWSC policy to send in all measurement data from the field by email, which requires a complete and accurate calculation of discharge. 


\section{Archival of ADCP Data}

All measurements, regardless of the method of data collection or instrument used, are archived as described in the section titled "Storing and Presentation of Hydrologic DataArchiving." For ADCP measurements it is necessary to store all files created as part of the measurement, regardless of their use, including any files output by utility computer programs to analyze the measurement, and a digital printout of the processing notes. The preferred file format for the processing notes is PDF.

\section{Review of Measurements}

Measurements made with an ADCP must be reviewed by an experienced ADCP user. This review process ensures that proper methods and policies were followed when the data were collected, and that any deviation from policy is clearly described in the processing notes, as well as taken into account when rating the quality of measurement.

\section{Measurement Using Parshall-Flume}

Portable Parshall measuring flumes are used when measuring shallow streams with low velocities in channels that can be directed through the flume without loss of water due to seepage bypassing the flume (Turnipseed and Sauer, 2010, p. 83).

Accuracy in flume measurements is highly dependent on the level installation of the flume, and that the flow has been allowed to stabilize following installation of the flume. Measurement error also is reduced by taking multiple samples of head readings in the flume at 30-second intervals after the flow has stabilized. A total of 3 minutes of sampling at 30-second intervals should be averaged. The flumes used by the KSWSC are 3 inch flumes, which can measure between 0.001 and $0.5 \mathrm{ft}^{3} / \mathrm{s}$ of flow.

\section{Volumetric Measurement}

Volumetric measurements are the most accurate method for measuring small discharges in a stream. The premise of the volumetric measurement method is to measure the time necessary to fill a container to a known volume. Difficulties present themselves, however, when trying to divert water in a natural channel into a container. This method typically works best when it can be made at a V-notch weir or at locations where a small earth dam can be constructed to divert all flow through a small pipe and into the container. If a small earth dam is required to collect the entire flow, the stage behind the dam must be allowed to stabilize before proceeding with the measurement. Three measurements of discharge should be made to ensure consistent results, and then the results of those three measurements averaged together to get the final measured discharge. The graduated container used when making a volumetric measurement should always be calibrated before the initial use for measurement. Details on how to calibrate a container are described in Turnipseed and Sauer (2010, p. 85). Time of measurement should always be determined using a stopwatch.

\section{Float Measurements}

In circumstances where shallow depth prevents the proper function of a current meter or ADV, but the stream cannot be channelized such to provide an accurate measurement using a Parshall-Flume or volumetric methods, then a float measurement is the preferred method for estimating streamflow. Float measurements can also be used to approximate flow in conditions that are not low flow, however use of the method should be restricted to instances when the standard equipment and methods fail or are unable to be used for one reason or another.

The accuracy of the measurement increases as the distance travelled increases, therefore the reach over which the float travels should be made as long as possible allowing for a uniform channel with no obstacles or eddies on which the float may become caught, and ideally be a minimum of $10 \mathrm{ft}$.

Time of float must always be measured with a stopwatch. Field notes should always include details on wind speed and direction at the measuring section as the float and/or water surface may experience unsteady velocities due to wind, especially in locations with low water velocities. The average area must be calculated at a minimum of 5 locations along the reach travelled by the float including the upstream and downstream terminus. Details on how to make float measurements can be found in Turnipseed and Sauer (2010, p. 85-86).

\section{Indirect Measurements of Discharge}

In some situations, especially during floods, it is impossible or impractical to directly measure discharge. There may not be sufficient warning for personnel to reach the site to make a direct measurement, or physical access to the site during the flood may not be feasible.

A peak discharge determined by indirect methods is in many situations the best available means of defining the upper portions of the stage-discharge relation at a site. Because extrapolation of a stage-discharge relation, or rating, beyond twice the measured discharge at a gaging station is undesirable and may be unreliable, discharge measurements made by indirect methods during periods of high flows are important forms of data (Rantz and others, 1982, p. 334).

The KSWSC follows data-collection and computation procedures presented in Benson and Dalrymple (1967). That report includes policies and procedures related to site selection, onsite survey, identification of high-water marks, the selection of roughness coefficients, computations, and the written summary. The KSWSC also follows procedures for measurement of peak discharge by indirect methods presented in Rantz and others (1982, p. 273). 
In addition to the general procedures presented in Benson and Dalrymple (1967), the KSWSC follows guidelines presented in other reports that describe specific types of indirect measurements suited to specific types of flow conditions. The slope-area method is described in Barnes (1967) and Dalrymple and Benson (1967). The USGS applies the Manning equation in application of the slope-area method. Procedures for selecting the roughness coefficient are described in Arcement and Schneider (1989). The computer-based tool, SAC, used for slope-area computation is discussed in Office of Surface Water memorandum 96.03 and is documented in a report by Fulford (1994). A SAC GUI version of the computer model is also available at (http://water.usgs.gov/software/SAC/). Procedures for the determination of peak discharge through culverts, based on a classification system that delineates six types of flow, is described in Bodhaine (1982). The computerbased tool, CAP, available to assist in computation of peak discharge at culverts is discussed in Office of Surface Water memorandum 96.04 and is documented in a report by Fulford (1998). At sites where open-channel width contractions occur, such as flow through a bridge structure, peak discharge can be measured with methods described in Matthai (1967) and with the water-surface profile computation model (WSPRO) (Shearman, 1990). Debris-flow conditions, which are most common in small mountainous basins, are discussed in Office of Surface Water memorandum 92.11.

Determinations of water-surface profiles along a stream channel in association with selected discharges are made when studies are done that involve delineations of flood plains or when extensions are made to stage-discharge relations at streamflow sites. USGS personnel are required to follow the procedures associated with step-backwater methods described in Davidian (1984). The computer-based tool used for assisting in the computations of water-surface profiles with stepbackwater methods, WSPRO, is discussed in Office of Surface Water memorandum 87.05.

General guidelines that are followed by the KSWSC when making indirect measurements include those discussed in Shearman (1990) and in Office of Surface Water memorandum 92.10. Violation of any one of the general guidelines does not necessarily invalidate an indirect measurement (Office of Surface Water memorandum 92.10).

The responsibility for ensuring that indirect measurements are performed correctly is held by Kansas Surface Water Specialist. It is required that a review of procedures and documentation be performed prior to publication of the data or use in any interpretive study. Reviews usually are done by the surface water specialist or another designated experienced surface-water hydrologist. All data associated with the indirect measurement are reviewed, including the high-water mark determinations, level notes, $\mathrm{n}$-value determinations, and hydrologic computations. All indirect measurements done by the KSWSC are reviewed. Measurements that are questionable and difficult to assess are reviewed by USGS regional surfacewater specialists, and the Kansas Surface Water Specialist is responsible for ensuring that deficiencies identified by the outside party are corrected.

Determining when and where indirect measurements are made is the responsibility of the Director on recommendations from the Data Chief. For the KSWSC, it is a general rule that indirect measurements are made at sites when peak flow at a site is estimated to be at least twice the discharge of the greatest measured flow or when needed at ungaged sites in support of interpretive studies of flood documentation.

It is the responsibility of the Chief-of-Party (of the indirect measurement survey) or a trained senior technician to identify and flag high-water marks. Because the quality and clarity of high-water marks are best marked soon after a flood, personnel traveling to gaging sites are required to have available in their vehicles nails and plastic markers, spray paint, paint sticks, and survey flagging.

After each indirect measurement is computed, the graphs, field notes and data, plotted profiles; maps, calculations or computer output, and written analysis associated with the measurement are checked by an experienced surface-water hydrologist. The information is stored in the directory in the location \ligskqdewgs002\KS_Data_Dir|KSWSC_general\ Indirect_Discharge_Measurements; available on request. Any paper notes used during the indirect discharge measurement should be digitally scanned and stored electronically within the aforementioned directory.

The responsibility of maintaining the accuracy of the peak-flow data files, including computer database files, lies with the KSWSC (Office of Surface Water memorandum 92.10). It is the responsibility of the Data Chief to ensure that appropriate indirect-measurement results are entered into the peak-flow files. It is the responsibility of the Surface Water Specialist to ensure that the peak-flow files are correct.

\section{Gage Height of Zero Flow}

The gage height at the point on a low flow control at which the stream will stop flowing is known as the Gage Height of Zero Flow (GZF). This point is found by measuring the deepest point in the stream at the upper terminus of a section control. The depth as measured is then subtracted from the gage height at the time of the measurement to obtain the GZF. Knowing the GZF and how it has changed over time is beneficial for many aspects of record working. During periods when a stream is on the verge of going dry, having an accurate GZF can yield higher quality measurements than the often poor measuring conditions available in such conditions. The GZF is an integral piece to rating development as it is closely related to the offset of the rating in the section control portion. Comparison of the GZF over time can offer the most insight into changes to the section control as it undergoes scouring or filling and is often the only way to explain changes to the shift diagram resultant from scouring or filling with clear control conditions. Continued lowering of a GZF can indicate that degradation of the channel is occurring and that a new rating 
is therefore warranted. For these many reasons, it is KSWSC policy that a GZF is to be obtained every time that it can be done safely, accurately and efficiently. The estimated accuracy of the GZF measurement should be noted on the field forms, and ideally it should be plus or minus $0.10 \mathrm{ft}$ or less.

\section{Field Notes}

The KSWSC uses the SV Mobile computer program to record field notes. It is the policy of the KSWSC that all discharge measurements are calculated in their entirety (including any needed corrections for moving bed or other factors) before personnel leave the site, unless emergency evacuation is required for reasons of safety. Measurements and site inspections (including field form files and files created in association with instruments) are to be sent in from the field by email whenever possible. It is the duty of the Field Office Chief to establish a designee who will receive field notes, enter the field notes into the database, and apply any data corrections or shifts necessary based on the data received. Although Office of Surface Water Technical Memorandum 2014.08 allows for up to 2 business days for measurements not within rated accuracy to the data displayed on NWISWeb or up to 7 business days for measurements that are within rated accuracy to the data displayed on NWISWeb, to best meet the needs of our cooperators and the general public the requirements within the KSWSC are more strict. All discharge measurement field notes, with all mandatory items filled in, must be entered into the NWIS database within 24 hours of a measurement being made - ideally within 1 hour after the measurement is made.

Because of deficiencies in the data collection fields of the SV Mobile program (and NWIS) comment fields are largely used to provide thorough explanations of the data collected. For example, gage height readings offer no location for data corrections to be appended to the field note; therefore it is necessary for gage height corrections to be described in the comment field associated with the sensor being corrected. The goal is to be able to easily compare primary recording gage readings with reference gage readings to determine if a data correction is applied appropriately; therefore, it is preferable to compare corrected readings of reference gages to uncorrected readings of the primary recording gage. All raw readings from reference gages should be contained in the comment field for the reference gage, with a description of any corrections applied. Corrected readings for the reference gage go in the actual gage reading field. For primary recording gage readings, the reading in the actual gage reading field is the reading without any corrections applied, and the corrected values and description of the correction applied are recorded in the comment field for the primary recording gage.

\section{Archival of Field Notes and Measurement Files}

All field notes and measurement files must be placed on the network drive at \ligskqdewgs002\KS_Data_Dir\Station_ Specific; available on request, in the appropriate directory for the station and measurement within 8 working-hours of returning to the office from performing field work. Any field notes that were not successfully sent from the field must be entered into NWIS. If amendments to measurement files or field notes are necessary, these should be performed before record work is attempted.

\section{Record Working}

Streamflow records are computed by converting gage height record to discharge through application of stagedischarge ratings. Records are computed on a continual basis as much as possible to improve the accuracy of provisional records shown on the NWISweb, and to provide the most upto-date information possible to end users of the data.

\section{Station Analysis}

The end product of record working is the production of a station analysis that details the considerations taken into account when screening, correcting, adjusting, and estimating data for the record period to serve as a reference in case questions arise about the records at some future date (Rantz and others, 1982, p. 580). Details included in the record period station analysis are described in the following headers:

\section{Equipment}

The section of the record titled Equipment should be included for all record types whenever a change in equipment type or location deems it necessary. This includes changing the type of data collection platform, brand or model of equipment used, and any addition or removal of sensing equipment. When equipment is moved to a new location (such as an orifice that is substantially moved along the bank, moved from bank mounted to pier mounted, or a radar that is moved to a substantially different location along a bridge) a description of the change in location and reason for doing so should be included, even if the equipment deployed remains the same. 


\section{Gage Height Record}

The section of the record titled Gage Height Record should be included in all surface-water sites (discharge, stage only and reservoir sites). Contents of this section should describe the overall quality of the gage height record collected for the period including periods and dates of erroneous data, estimated data, and missing data. Description of the estimated data should include methods by which the data was estimated, as well as the evidence used by the record worker to determine that estimation was necessary. Actual corrections to the gage height record are reserved for a separate section of the analysis.

\section{Groundwater Elevation Record}

The groundwater elevation record section is the equivalent for groundwater sites to the gage height record section for surface-water sites.

\section{Datum and Gage Height Corrections}

All record types (surface water and groundwater) should include a record section on datum and gage height corrections. In this section should list the last time that levels were run and any datum or gage height corrections applied (or not applied) to the record. If levels were run, describe the results and actions taken. For gage height corrections, describe the cause of the correction and the timing of the correction. Long-term corrections, such as those to a wire weight gage or for drawdown of an orifice, should remain static within this section with a description of the time periods or site visits used to derive the drawdown correction and reasoning for not using any inspections performed that were excluded during that time period.

\section{Peak Verification}

A record section describing verifications of peak stage should be included for all stream flow sites (discharge and stage only record sites). This section should list the peak as recorded by the primary recording gage during the record period, the minimum recording elevation of any crest stage indicators in place at the site, and any peak stages recorded by those crest stage indicators during the record period. If the stage of the stream exceeds the minimum recording elevation of the crest stage indicator, but a peak was not recorded by the indicator, then a description should be included pertaining to why the crest stage indicator failed. If the peak stage is found by a high water mark not associated with a crest stage indicator then the nature of the high water mark should be described.

\section{Ratings and Shifts}

All discharge sites should include a record section discussing ratings used for discharge calculations and the shifting of those ratings. This discussion should include notation of measurements used to develop the ratings (either in specific terms of measurement numbers or more general terms of time periods included with a description of excluded similar measurements) for record periods when a new rating was implemented. The rating description should include mention of the physical changes to the stream that warranted the development of the new rating; for example, bank slump resulting in a need to redraw the channel control portion of the rating. The date on which the rating was first implemented should be retained in record analyses from record period to record period.

Shift analyses should describe any shifts that were necessary to be applied to the rating or deemed not necessary to be applied to the rating. This description should include mention of the measurements made during the record period, control conditions that the respective measurements were subject to, and comparison of those control conditions to previous field visits. Analysis of shift application should include field observations combined with examination of the discharge rating to describe how the shape of the shift adjusted rating was derived, as well as the factors used to determine timing of shift implementation.

Measurements that were made during the record period but are not being used to calculate discharge for any reason should have an explanation for the exclusion reported within this section of the record analysis.

\section{Hydrographic Comparison}

For sites where discharge is calculated, there should be a record section titled Hydrographic Comparison. This section contains a descriptive comparison of the calculated discharge for the site during the record period to an index site or sites either along the same stream or in the vicinity. The comparison should explain how well the sites compare with each other and reasons for the correlation between the sites weakening during parts of the record period if necessary. In some cases hydrographic comparison is not possible at a site because of the site being highly subject to regulation or being extremely isolated geographically, in which case the hydrographic comparison section should explain why no good index site can be found.

\section{Special Computations of Discharge}

For sites where discharge is published, a record section titled Special Computations of Discharge is written to describe discharge data that has been computed by means other than 
with the ratings. This section should describe what time periods, if any, during the record period required estimation, the characteristics which influenced the hydrographers to perform the estimation, and the means by which estimation was performed. If data appears unnatural but is decided not to be estimated, it should be mentioned in this section with a remark stating why it was determined to be true and accurate data.

\section{Remarks}

All record types should include a section dedicated to any special remarks for the site and record period. There are no required items which must be discussed in this section; rather it is used to detail special situations which may be occurring at the site not covered in other sections of the analysis.

\section{Water Year Peak}

For the record period which crosses into a new water at streamflow sites (not lake/reservoir sites), a section is included titled Water Year Peak. In this section is described the peak recorded stage for the forgoing water year, the date on which the peak occurred, and any substantiating data obtained regarding the peak.

\section{Well Integrity Test}

A record section titled Well Integrity Test should be included listing the date and time of the most recent well integrity test. If a well integrity test was performed during the record period, then the analysis should include a full report detailing what type of test was performed and the results of the test, as well as comparison(s) to previous test(s).

\section{Reservoir Contents}

Reservoir contents are generally computed for most reservoir sites within the KSWSC. For these sites a Reservoir Contents record section is included listing the rating in use during the period, the date on which that rating was implemented, and the agency which developed the rating.

\section{Special Computations of Elevation or Contents}

The Special Computations of Elevation or Contents record section is included in analyses for reservoir sites listing the dates which have had the elevation or contents estimated, the reason that estimation was necessary, and the methods used to perform the estimation.

\section{Data Record}

The Data Record section of the record is a section specific to index velocity sites comparable to the Gage Height Record section at other streamflow sites. This section is used to detail the quality of the data record for the period with regards to the velocity data collected, gage height data collected, and discussion of automatically collected beam check tests looking for any obstacles which may have interfered with the quality of the velocity data during the record period.

\section{Monitoring Program}

A record section titled Monitoring Program is included for precipitation records. This section describes the cooperator for the precipitation data, as well as the specific needs of the cooperator (for example, total precipitation for day, maximum precipitation for a period, liquid precipitation only or liquid and frozen precipitation).

\section{Precipitation Record}

The Precipitation Record section of the record is included for precipitation sites. This section describes the general quality and completeness of the data for the record period listing dates which have diminished quality data or missing data.

\section{Quality Assurance}

The Quality Assurance record section is included for precipitation record sites and describes the field inspections and calibrations that were performed during the record period and any adjustments or corrections that were required as a result thereof.

\section{Estimation of Precipitation Events}

Any days of estimated precipitation are mentioned in a record section titled Estimation of Precipitation Events including dates and methods of estimation.

\section{Record Working Duties}

It is the responsibility of the hydrographer who performed the field work to finish any field notes and process all measurements and levels to the point of completion before the record can be worked; all entries to databases, archival of electronic files, and any other storage and updating of data collected, such as levels summaries, is to be completed by the party whom collected the data. 
The hydrographer working the record is responsible for applying any gage height corrections necessary, and screening, flagging or estimating erroneous gage height record as necessary, including radar dips. The reasoning and timing for any gage height corrections should be clearly described in the Gage Height Corrections section of the station analysis for the record period.

Examination of gage height records should include any peak verification data obtained during the record period. Comparison of peak data from high water marks and crest stage indicators to the primary recording gage data can indicate if the primary recording gage was working properly during the rise, and assist in estimating record when the sensor for the primary recording gage is damaged during an event.

After an accurate record of gage height has been established, the record worker should apply any shifts or develop a new rating if necessary, based on the measurements made and hydrologic conditions and events during and before the period of record being worked. All applications of shifts or new ratings should be clearly described in the Ratings and Shifts section of the station analysis for the record period.

Once any necessary shifts have been applied, days with missing or erroneous data should be estimated and the methods and reasoning of estimations described within the Special Computations of Discharge section of the station analysis.

\section{Record Working Procedures}

\section{Gage Height Record}

A record of gage height readings is necessary to develop a continuous record of discharge using the stage-discharge relationship developed for discharge gages. Occasionally gages are subject to errors, which require manual editing or estimating of the erroneous gage height record. This occurs when radar gages read to troughs in waves, resulting in periodic erroneously low values known as radar dips, and when pressure transducer gages become covered in sediment, resulting in short term erroneously high values. When these types of problems occur, the true stage that should have been measured is generally still apparent in the record, even though individual readings may be erratic and do not match the reference gage. The gage height record can be edited or estimated by smoothing the erratic data and connecting it with good adjacent data, following the trend in stage. An explanation of when edited or smoothed gage height record should be flagged as estimated is explained in the section of this document titled "Estimating Gage Height Record."

\section{Erroneous Gage Height Record}

When working hydrologic records, the gage height is examined for readings that are much greater or less than the surrounding data. Readings that are determined to not be representative of the true stage at that time, and cannot be corrected by application of a gage height correction or accurately estimated, are deleted from the "edited value" record in NWIS.

\section{Gage Height Corrections}

Gage height corrections can be resultant from movement of the gaging structures, drifting in the calibration of the gaging instruments, or problems related to the location of the instrumentation (such as drawdown).

Gage height corrections should be applied any time that the primary recorder does not match the reference gage within $0.01 \mathrm{ft}$, for conditions that provide comparable and accurate readings. Reference gage readings to ice, and readings during times of rapidly changing flow when the stage may change in the time it takes to make readings of both gages, are exempt from gage height corrections because of the unreliable data and poor comparability between gages present in those situations. If either gage reading has a plus or minus error of greater than $0.01 \mathrm{ft}$ (such as a wire weight reading to a water surface with waves), the magnitude of that plus or minus error then becomes the minimum difference between gage readings for a data correction to be applied.

It is possible that a discharge measurement will plot outside the allowable percent away from the corresponding continuous-record instantaneous discharge value after proper shifting (based on the reference gage height) has been applied, even when the gages read within $0.01 \mathrm{ft}$. In such cases, if applying that correction for a difference of plus or minus $0.01 \mathrm{ft}$ between the reference and primary recording gages brings the continuous-record instantaneous discharge value to within of the allowable difference from the measurement, it must be applied. For instance, if a measurement is made and rated good with the primary gage reading $0.94 \mathrm{ft}$ and the reference gage reading $0.95 \mathrm{ft}$; however, at that stage the stagedischarge rating for that station is sensitive such that a $0.01 \mathrm{ft}$ difference in stage results in a 6 percent change in discharge, then a plus $0.01 \mathrm{ft}$ gage height correction is necessary to bring the real-time discharge to within the allowable error of the measurement.

\section{Single-Point Gage Height Corrections}

Corrections that are due to the vertical movement of some part of the gaging structure should consist of a single point correction, which is in place throughout all stages. These corrections are likely to be caused by an event (orifice struck by floating debris, orifice moved by ice, algal growth over an orifice resulting in consistent partial plugging), and should be put into use at the time that the event is estimated to have occurred. Some events occur gradually, and therefore a proration is the most appropriate method of correction application. If the event occurred before the current period, the correction should be put into place at the beginning of the current period, with a corresponding shift change if necessary. Data corrections should never be prorated over time simply for the purpose of smoothing or hiding their application; instead they should be started immediately at the earliest time data are not 
in "approved" status when it is believed the correction should have been in effect.

\section{Variable Stage Gage Height Corrections}

Variable stage gage height corrections are sometimes necessary in situations where the difference between the actual and correct readings of a gage changes as the stage increases or decreases. An example of this is correcting for draw down of a non-submersible pressure transducer or stilling well because of the Venturi effect, which increases as stream velocity increases. These variable stage gage height corrections are constructed by examining the differences between the primary recording and reference gages over a period of time long enough to provide multiple comparisons throughout a range of stage, but not so long that a physical change has occurred to the configuration of the gages, which would cause the comparison data to be invalid. It is therefore necessary to document changes to the orifice, such as moving the orifice location from a pier to the stream bank, from one stream bank to the other, or significant vertical or horizontal changes in position of the orifice that would change the velocity profile in the vicinity of the orifice. Additionally, changes within the stream, such as bank slump, can result in a change to the velocity profile in a stream. Any changes that occur in the location of the orifice should be documented in the station analysis for that period in the Equipment paragraph of the record.

Variable stage gage height corrections should be examined for validity on a regular basis as part of the record working, checking, and reviewing process. The responsible party for each step of the process should examine variable stage corrections every time that a new data point in the correction range is made available.

A spreadsheet is available to assist in creating these variable stage corrections, and to document the data points used. This spreadsheet is titled "Variable_Corrections.xlsx" and can be found at \ligskqdewgs002\KS_Data_Dir|KSWSC_general\ Software; available on request. Inputs to the spreadsheet are raw readings from the primary recording gage, readings from the reference gage (corrected if necessary), and the date of the inspection. Data points included on the spreadsheet should only be from times when the primary recording gage was reading different than the reference gage. Use of zero correction readings will skew the results of the linear regression being applied making it not representative of the data where a correction is necessary. Calculations performed on the spreadsheet determine the difference between the primary recording and reference gages, plot the difference versus stage, apply a linear regression to determine the stage at which the correction begins, and give the points necessary to be input into NWIS to correctly apply the linear correction.

As the correction is a result of changing velocity in the vicinity of the orifice, it is likely that at some unknown point the water velocity in the vicinity of the orifice reaches a maximum and is no longer affected by a change in stage. It is for this reason that close visual examination of the data points as they lie on the plot should be performed, checking for a break over point at the upper end where the magnitude of correction remains relatively stable.

Variable stage corrections should be input to NWIS as two point type 2 corrections. The correction should have a magnitude of zero at the lower end. The stage input for the upper end should be higher than any stage values reported by the gage during the period in question with a magnitude determined by extrapolating the linear equation out to that stage.

\section{Estimating Gage Height Record}

Gage height record can be estimated at times when gage height data has been semi-accurately collected; however, the quality of that data is degraded due to deficiencies in the primary recording gage. Examples of deficiencies in the primary recording gage are orifices that become covered in sediment, or radar gages that are subject to radar dips. Estimates should be performed by following the trend between good adjacent readings that are not affected by the errors that cause the estimation. When estimating for a covered orifice, this is generally accomplished by drawing a line connecting the lowest readings during the time the orifice is covered. During times that radar stage sensors are subject to radar dips, generally the trend of stage is recorded; however, many of the values are lower than the good adjacent data. Therefore to estimate gage height record for radar dips, a line should be drawn from the last good reading to the next reading not affected by radar dips following the trend in stage.

All values of corrected gage height record will retain the default flagging of "marked as estimated" in ADAPS.

Except at lake gages, mean daily gage height values are never directly estimated by the hydrographers, only instantaneous gage height values. The estimation of daily gage height values may, however, result in a mean daily value, which is marked as estimated by default.

If a long term data loss occurs at a lake gage, or if a short term data loss occurs at a lake gage when adjacent data is not of high enough quality to estimate the individual value gage height record, then the final daily gage height value should be estimated with a daily value remark code of "e" applied.

Special care must be taken prior to finalizing the working of a record period to ensure that no gage height record was estimated prior to a gage height correction being applied to the record period as estimated values will not be corrected automatically.

\section{Peak Gage Height Record Obtained From Auxiliary Data}

Estimation of gage height record can also include adding an alternative reading of peak stage when the primary recording gage failed to record a peak. Alternative readings of peak stage include high water marks, crest stage indicator peaks, or a direct reading of a reference gage at the time of a peak. The estimated instantaneous value is entered into NWIS at the time the peak is judged to have occurred. As this value is derived from a reading of the reference gage or an auxiliary gage it should be write-protected in NWIS. 


\section{Rating and Shifts}

The determination of the stage-discharge relation and associated development of the rating is one of the fundamental tasks in computing a discharge record. The rating is usually the relation between gage height and discharge (simple rating). Ratings for some special sites involve additional factors such as rate of change in stage, or fall in slope reach (complex ratings) (Kennedy, 1983, p. 14).

USGS personnel follow procedures for the development, modification, and application of ratings that are described in Kennedy (1984). Personnel also follow guidelines pertaining to rating and records computation that are presented in Rantz and others (1982, chap. 10-14 and p. 549) and in Kennedy (1983, p. 14). The software application GRSAT is used for rating development and shift analysis.

For each gaging station, the current rating table is available in NWIS, as well as many historic ratings. Ratings are reviewed during records review.

Each rating at a station is given a unique identification number beginning with 1 . New ratings that are the result of (1) a physical change in the stage-discharge relation, (2) extensions of old ratings, or (3) are corrections to minor errors in old ratings that have already been approved and therefore cannot be changed. These new ratings are given a new identification number of the next unit higher. Any questions related to station ratings should be directed to the Field Office Chief or the Data Chief.

Ratings may be subject to an upper-end extension of no more than 2.5 times the highest directly measured discharge assuming that extension of the rating makes hydrologic sense based on observations of the controlling features of the stream, and extension on the lower end to one-fourth of the lowest directly measured discharge or to zero flow if the lowest measured discharge is $1 \mathrm{ft}^{3} / \mathrm{s}$ or lower or if a gage height of zero flow has been obtained with an accuracy of at least plus or minus $0.03 \mathrm{ft}$.

Measurements that are not within the respective error bounds to the rating must have a shift implemented to the rating which is within the error bounds of the measurement unless the measurement is marked as "Do Not Use" in the database. This shift application should be put into place within 1 hour of the measurement being entered into the database, so that the discharge data displayed in real-time are as accurate as possible based on what is known at the time. Development of the shift diagram used should take into account the physical cause for the shift, and at what point this feature would no longer affect the stage-discharge relationship. Likewise, the physical cause of the shift must be taken into account when determining the proper timing for shift application.

At times of ice-affected control conditions, backwater, beaver dams, or other conditions which render the stage discharge relationship invalid, shifts to the rating should not be applied; instead the discharge during these periods of time should be estimated. Shifts should not be applied to measurements which have been marked in the database as "Do Not Use."

\section{Measurements Marked as Do Not Use}

Measurements which have been marked as "Do Not Use" in the database should have clear documentation within the measurement comments describing the reasons that the data is considered to be erroneous. When drawing ratings and shifts, these measurements should be completely disregarded. Unused measurements should have a description in the station analysis for the period during which the measurement was made explaining the ways that the measurement data is erroneous. A record period must not be worked up to the time of an unused measurement until a satisfactory measurement has been obtained for discharge sites.

\section{Estimating Discharge for Periodic Errors}

Instantaneous values of discharge may be estimated to correct for short duration losses of data or to correct for short duration periods of erroneous discharge record. Although it is acceptable to estimate longer periods of discharge by estimating instantaneous discharge values, the practicality of doing so diminishes for durations lasting more than 3 consecutive days. Estimation for short periods of time is generally based on trend of flow and local precipitation data for the location. The daily discharge value may be write-protected if the discharge changes by less than 10 percent throughout the estimated period and the day that is write-protected has at least 12 consecutive hours of record of not being estimated.

\section{Estimating for Persistent Errors}

When the stage-discharge relationship at a site is temporarily too unstable or uncertain to adequately compute streamflow from the record of stage, or when the stage record itself is incomplete or erroneous and cannot be estimated for use in discharge computations, discharge values must be estimated. The most common conditions that negatively affect the stagedischarge relationship are beaver dams, the presence of ice in the channel or on the control, and variable backwater from a confluence or impoundment downstream. If any of these conditions are recognized to be occurring, the discharge record must be estimated at the station and measurements must be made more frequently to aide in those estimations.

\section{Estimating Discharge Because of Backwater From Ice}

Estimating discharge because of backwater from ice requires close comparison to meteorological conditions and events that occur during the period of estimation, comparison with discharge measurements at the gaging station, comparison to nearby stream gages that remained free of ice during the period in question, and taking into account releases from 
reservoirs if relevant. Estimation of discharge when ice is present in the stream is only necessary when ice in the channel or on the control causes the stage to increase. There are a couple of conditions described later in this section (ice damming or ice storage upstream from the gage), which can cause the stage and flow to decrease at the gage. When this happens, the record is normally good, and should not be estimated.

Ice forming in the channel or collecting on the control can result in backwater at the gaging station. As the gage height record during times of backwater is still accurate, no gage height record should be estimated. Shifts to the rating are not an allowable method of correcting or estimating discharge affected by backwater from ice.

\section{Ice Damming Upstream From the Gaging Location}

It is possible for an ice dam to form upstream from the gaging site resulting in a temporary decrease in flow as evident by a drop in gage height at the gaging station. Typically this ice dam upstream will eventually break loose resulting in a rise in the streamflow at the gaging station. In a situation such as this, as long as ice does not collect in the channel at or below the gage or on the control resulting in backwater, no estimation is necessary. It can be determined if backwater resulted as the ice dam passed through the control by applying continuity of mass to the streamflow over the period in question; the amount of water stored by the ice dam upstream should be equal to the amount of water that passes through the control when it breaks up.

\section{Temporary Loss of Discharge to Ice Storage}

A portion of the streamflow can also be stored (held back) in the channel in the form of ice; therefore, meteorological conditions should be taken into account to explain oscillations in the trend of discharge values. It is common for sharp drops in temperature, especially during periods with little sunshine, to result in an increased portion of the streamflow being stored as ice in the channel, resulting in a decrease in streamflow. Conversely, a period of warm air temperatures with sunny days to melt some of the ice in the channel can result in an increase in streamflow, even when there is no precipitation at the time.

When these events happen upstream from a streamgage that has little or no backwater effect from ice itself, the stages recorded by the streamgage can be used to accurately compute the record of streamflow that has these fluctuations because of upstream freezing and thawing. To verify that the record of flow computed by the gage is accurately accounting for storage and releases of flow from ice, and not affected by backwater from ice itself, compare the volume of water lost to storage when the stream freezes to the volume of water that melts later on. Although this comparison is not always simple to determine, and there are complicating factors at times, in general this gives a good indication of the accuracy of the flows at the gage when these situations occur (as well as providing evidence of the occurrence).

\section{Estimating Discharge Because Of Variable Backwater Caused by Beaver Dams}

Beaver dams create a dynamic obstacle for determining streamflow using a stage discharge relationship. The presence of beaver activity in a stream can result in backwater at the gaging station and decreased quality of measuring sections because damming the stream slows water velocities. The backwater from beaver dams is different from that created by ice in that the beaver dam activity acts independently from weather phenomena, or any measurable criteria that can be monitored on a large scale. With the problems of backwater restricted to areas that have beavers active in them, it is possible that the streamflow at a gaging station affected by unstable control conditions from beaver activity can be fairly accurately estimated by comparison to the flow at another station nearby which is not affected by a beaver dam. Beaver dams tend to cause the most severe problems on smaller streams and during low flow conditions. The amount of backwater induced by a beaver dam is dependent on the size and make-up of the beaver dam in question. Beaver dams are often constructed and maintained on a continual basis, therefore a measurement of discharge indicates the particular shift at a given point in time, but that shift may be invalidated by beavers (or other factors) modifying the dam following completion of the measurement.

For times when beavers are active within a stream, the daily discharge must be estimated. Because of the length of time beaver dams affect the stage, and the variability in that affect, it is almost always impractical to estimate instantaneous values of discharge. It is possible for a beaver dam to be present in a stream without changes being made to the dam by beavers or other factors, resulting in a stable stage-discharge relationship. The described stable situation can be reliably and accurately shifted to in most situations. The resulting data is required to be marked as estimated only if confidence is low for the shift to appropriately calculate discharge throughout the range of stage while the shift is in place. For this and other reasons, it is KSWSC policy that beaver dams not be modified or removed by KSWSC staff, unless there is strong evidence that beavers will not build back a dam in the vicinity at any time in the near future. Methods for estimating of beaver dam-affected discharge record are somewhat similar to those used to estimate discharge for ice record, however all considerations for temperature and ice storage and melting can be disregarded.

It is KSWSC policy that shifting of ratings not be used to account for changes to beaver dams. The timing and magnitude of shifts cannot be accurately determined from a record of stage and discharge. Also, using shifting to estimate record is more time consuming than graphical-comparison estimation of discharge records, and is no more accurate. Applying estimated shifts based on changes in stage that are assumed to be changes to the control, in an attempt to improve realtime discharge values displayed on the internet, also is not allowed - be it because of beaver activity in the stream, or anything else. 


\section{Thresholds}

Thresholds in NWIS are used to prevent unrealistic readings from gages from making it into the database. In accordance with the Office of Surface Water Technical Memorandum 2014.03, all sites are to have thresholds set at the lowest possible value that the instrumentation can accurately read, and at the highest possible value that the instrumentation can accurately read. These thresholds, which belong under the Very Low (VLO) and Very High (VHI) threshold fields in the software, should contain the character string (POL), including the parentheses, in the LVH Label (Very High Threshold Label) and LVL Label (Very Low Threshold Label). This string signals approval for displaying the threshold as a reference line to the public on NWISweb hydrograph plots. The KSWSC additionally requires that all stage or elevation data descriptors have Very Rapid Increase (VI) and Very Rapid Decrease (VD) thresholds set to 0.24 feet per minute, to block erroneous single IV spikes from making it into the database, and prevent sites from being reported in the OSW spike reports. In the event that the VI or VD thresholds screen out accurate data on a very flashy stream, the data that has been screened out should have the erroneous flagging removed as soon as possible for inclusion in the dataset and for display on NWISWeb.

For pressure transducers, the highest possible value is either the point at which the pressure transducer reaches maximum pressure (generally $15 \mathrm{psi}$ or $30 \mathrm{psi}$ ), or the point at which the equipment in the gage house would become inundated. At these sites, the VHI threshold should be set to this stage and have the label "(POL)" so that the maximum operating limits of the gage will be displayed as a reference line on the hydrograph in NWISweb. The lowest possible value at these sites is determined by the elevation of the bubbler orifice or submersible transducer sensor. If the pressure transducer is installed at a site, which is not subject to going dry, the VLO threshold should be set to $0.02 \mathrm{ft}$ higher than this lowest possible reading and the LVL Label should include the character string (POL), including the parentheses. If the pressure transducer is installed at a site, which may be subject to going dry , then the VLO threshold should be set 1 foot lower than the elevation of the orifice or offset, and the LVL Label should NOT include the character string (POL), but instead state "reference line is set in nw_edit." So that the public are notified of the operating limits for the gage in NWISweb, a reference line must be manually set and maintained in nw_edit with the label "Operating limit (minimum)" at the stage $0.02 \mathrm{ft}$ higher than the elevation of the orifice or offset.

For radar gages, the highest possible stage value is generally 1 foot below the elevation of the radar, or the point at which the equipment in the gage house would become inundated (whichever is lowest). At these sites, the VHI threshold should be set to this stage and have the label (POL), including the parentheses. The VLO threshold at these sites should be set to the stage at which radar readings are considered to definitely be invalid because of interference by the stream bed, and should NOT have the (POL) label, but instead state "reference line is set in nw_edit." So that the public are notified of the gage's operating limits in NWISweb, a reference line must be manually set and maintained in nw_edit with the label "Operating limit (minimum)" at the stage below that it is estimated that the radar begins to be affected by interference from the stream bed.

\section{Special Circumstances}

\section{Seiching of Lakes}

Lakes are subject to seiching, an oscillation of the surface of a landlocked body of water. Seiching can result in the gage height fluctuating up and down a few hundredths or even tenths of a foot, lasting for up to several hours. The cause for such fluctuations is wind pushing the surface water either toward or away from the area of the lake where the stage sensor is deployed. When this action is sustained it leads to an increase or decrease in stage for the lake in the vicinity of the sensor as the water piles up at the down-wind shoreline. Gage height record that is subject to this phenomenon should not be estimated or edited; rather the mean daily values of lake water surface elevation and contents should include any values subject to seiching.

\section{Inland-River Storm Surge}

On rare occasions, in very special conditions, a phenomenon that likely has no official name occurs that affects the stage record at streamgages. Strong persistent winds can drive water in a stream downwind, which can have the effect of increasing the flow when the wind is blowing downstream or decreasing the flow when the wind is blowing upstream. In both of these cases, the stage discharge relationship likely is not substantially affected. If the wind is blowing perpendicular to the streamflow direction however, the water in the stream can pile up on one bank or the other. When this happens, and the stage sensor is located on or very near a bank, the stage at the sensor will be higher or lower than the mean stage in that cross section of the stream. This condition does affect the stage-discharge relationship, because although the flow rate likely remains steady, the stage at the sensor either increases or decreases. This phenomenon is most common on larger streams without good protection from the wind, when stream velocities are low, and the stream is shallow; though it can happen in other conditions.

When temporary and unexpected increases or decreases in stage occur in a stream-stage record, wind-driven water must always be considered as a possible cause. When the wind is pushing flow upstream or downstream, it should be mentioned in the station analysis for that period, but nothing should be changed in the record of data. When the wind is pushing water perpendicular to the normal streamflow direction and causing the stage sensor to measure a stage that 
is higher or lower than the mean stream stage in that cross section, then the individual values of stream stage during that period should be estimated based on the trend before and after the time of wind effect.

\section{Error Handling and Web Display}

Gages producing erroneous data or missing data should be repaired as quickly as possible to prevent large quantities of data loss, and to allow for real-time uses by the public and cooperators to be based on data that is as accurate and complete as possible. To prevent data that is knowingly erroneous from being displayed on the internet, erroneous parameters should be turned off on the Web using the program nw_edit. This program allows for the data to be restricted from view with a descriptive notation that indicates to the public why the data are not available. For stations where discharge is computed, both stage and discharge must be turned off when stage data is determined to be erroneous. The following are error codes which are considered acceptable for use in the KSWSC for the given circumstance:

Eqp - Equipment Malfunction, the equipment malfunction code is used when the stage sensor is subject to persistent erroneous readings, or data are not being received in the database for one reason or another.

Ice-Flow at station affected by ice, the flow at station affected by ice code should be used any time that the stage or discharge data is erroneous because of ice in the stream. The stage data may become erroneous because of a radar sensor reading on an ice covered surface, or when an orifice becomes encapsulated in ice. It is preferable to communicate that these errors in gage height are not caused by a problem with the equipment itself, but rather because of icy conditions in the stream, and therefore the gage cannot be repaired to provide proper stage data. The discharge should be turned off on the Web using this code any time that the stage is turned off using this code. If the discharge is affected by ice in the stream causing the stage-discharge relationship to be uncertain or unreliable, then only the discharge should be turned off on the Web.

Bkw-Flow affected by backwater, if a station is subject to backwater, the flow affected by backwater code should be used. Proper use of this descriptive code is restricted to backwater caused by a downstream confluence with another stream or reservoir. This code should attribute times when the discharge cannot be corrected by a change to the rating or shift, yet the discharge is not affected by ice.

Dis-Discontinued station, if a station has been discontinued, the discontinued station code should be used to indicate both stage and discharge is no longer available and the code should remain in use until the Data Chief determines real-time display of the station is no longer necessary.

***-Data temporarily unavailable, the data temporarily unavailable code is to be used any time that there is an issue requiring data to be masked that is not covered by other error codes. For example, this code may be used when a beaver dam results in unverified changes to the control.

\section{Checking Hydrologic Records}

Each hydrologic record is subject to a quality control process that involves checking of the record, and a review of the methods and procedures implemented for the record period. These assignments are made in RMS with the system automatically alerting record checkers/reviewers to the availability of new records assigned for checking/reviewing by email. It is the responsibility of the record checker to complete the following actions:

- (If levels were run during the record period) Examine the levels notes for adherence to levels policy; check any calculations not calculated automatically by the Station Levels program, and check that numbers have been correctly transferred from the field notes to the station description in SIMS and the results of levels summary file.

- Examine all field notes for accuracy, adherence to policy and completeness (including the transfer of discharge measurement data into SV Mobile/SiteVisit), adherence to policies and procedures on field data collection methods, and proper archival of files including levels notes, discharge measurements, and SV Mobile files.

- Ensure that all numbers from the station analysis match those in NWIS.

- Ensure that the timing and application of shifts applied in NWIS are accurately described in the station analysis, and that all days of missing or estimated record have been reported as such in the station analysis.

- Ensure that gage height corrections are checked for proper calculation and appropriate application.

Records which are determined to be in error by the record checker are returned to the record worker for rework.

\section{Reviewing Hydrologic Records}

Record reviews are performed on all records by Field Office Chiefs, senior technicians, or the Data Chief. The purpose of the review is to ensure that proper methods were applied throughout the process of obtaining the surface-water data and computing the record. It is the responsibility of the record reviewer to review the following: 
- Levels should be reviewed, if performed during the period, to ensure that all policies are followed. Records wherein the levels are more than 3 months overdue, or when levels policies were not fully satisfied, should not be approved until a proper set of levels are run and any needed changes made to the record.

- Changes or corrections by the individual checking the record.

- Ensure that both reference and recorder gages were read and compared, and that any necessary gage height corrections have been applied appropriately and described in the station analysis. If there is no comparison of the reference and recorder gages during or after the period, one must be obtained before the record can be appropriately worked and approved.

- Shift applications for appropriate implementation, taking into account descriptions of the control and changes to the control described in the station analysis and field notes.

- Check to ensure that the rating in use has been properly drawn and continues to accurately calculate discharge. Records should not be approved (or marked ready for checking for that matter) when ratings lack at least three discharge measurements with a stages of at least $0.5 \mathrm{ft}$ apart, when ratings are extended more than 2.5 times the highest measurement at the upper end, or when ratings are extended below one fourth of the lowest measurement on the lower end.

- Estimations and methods of estimation should be compared to trend of flow and compared to nearby index stations.

- Hydrographic comparison with other stations is used to examine estimated days, as well as compare shift applications and comparison of flows for consecutive stations along the same stream.

- Extremes of stage and discharge should be examined.

- The station description should be reviewed for completeness and accuracy during each period reviewed, as well as an especially thorough review for the first record period following the end of the water year.

- NWISweb manuscript pages for the station are checked for accuracy during each period reviewed, as well as an especially thorough review for the first record period following the end of the water year.

- Job hazard analysis should be reviewed every time that a change occurs affecting the traffic at the site, the conditions in the wading section, or an organizational change to the job hazard analysis is made. An additional thorough review takes place for the first record period following the end of the water year.
Necessary changes are coordinated among the parties, with the Data Chief resolving any disputes. When reviews are completed, the station status is changed to "Reviewed" in RMS and data aging status is set to "Approved" by the reviewer.

\section{Using swreview}

The KSWSC uses a program called swreview to assist with record reviews. Reviewers should use the output from this script to examine the following:

- That the individual value discharge hydrograph falls within the allowable percent from discharge measurements.

- For trends that may indicate that a longer term change to the control has been in place, or that an average shift may be appropriate to multiple measurements made in a given stage range.

- That discharge measurements are being made as needed to fill in definition gaps within the rating.

- The timing of any shifts applied to the rating, comparing with explanations for the shifts in the station analysis and field notes.

- The shape of the shifted rating to ensure that the shift returns to the rating in an appropriate manner and that the shift only applies to parts of the rating that should be affected by the reported physical change to the control.

- For any erroneous data that the record worker failed to flag as erroneous and ensures that all estimations are proper.

- The discharge hydrograph in relation to comparison site discharges.

- The accuracy and validity of the rating in use, the need for development of a new rating, and final approval of new ratings developed during the period.

Output from the script can be found at http://swr.cr.usgs.gov. Documentation describing swreview can be retrieved from http://water.usgs.gov/usgs/osw/adaps/swreview.html.

\section{Operation of Index Velocity Stations}

Stations where discharge is calculated using the index velocity method are subject to special criteria not relevant to stations where discharge is calculated using the typical stage-discharge method. Detailed methods for operation, maintenance, and quality assuring of an index velocity site are described in Levesque and Oberg (2012), as well as prescribed in Office of Surface Water memorandum 2012.04. Of particular note are some of the procedures required while performing 
routine maintenance, site visits, and discharge measurements. As the instruments used for collecting stream velocity data are hydroacoustic instruments, it is required that an independent water temperature be obtained for comparison with the logged water temperature every time that a site visit is performed. Also at each site visit the field person should perform a beam check test in the instrument and download the log of beam checks for archival. Each time that a discharge measurement is performed, the data in the ADVM should be set to log data at a 1 minute interval for the duration of the measurement. Whereas Office of Surface Water memorandum 2012.04 policy states that verification of the stage-area rating can be performed in 3-year intervals, it is policy in the KSWSC that the stage-area rating is checked for accuracy annually.

\section{Operation of Precipitation Gages}

Precipitation gages can be operated as either internal or public gaging stations. Gages operated for internal purposes receive no official quality assurance processes and are used only for aid in working of hydrologic records. Data from these precipitation gages must not be made available to the public because of the lack of quality assurance.

In contrast, publicly operated precipitation gages are generally funded by a cooperator and the data being publicly available are thereby subject to quality assurance processes described in this document.

\section{Field Procedures for Precipitation Gage Operation}

The calibration of precipitation gages must be tested at least once every 6 months. If the precipitation gage does not comply to within 5 percent of the test volume then adjustments to the tipping mechanism must be performed until the gage successfully reports within 5 percent of the test volume as recommended by Office of Surface Water Technical Memorandum 2006.01. If, after multiple attempts at calibrating a precipitation gage, 5 percent compliance cannot be achieved then the precipitation gage should be replaced with a gage that is within compliance.

The screen and cone of the precipitation gage should be inspected at every site visit with any debris that is found within the screen and cone removed. Tipping bucket gages should have the pivot hinge lubricated with a plastic-safe lubricant and the collector cone waxed with liquid car wax at the time that the calibration is tested. Inspection notes should always include verification the gage is level, there is a visual check of a 45 degrees or larger clearance above the collector, maintenance activities, 30 tip test wherein the tipping bucket is tipped 30 times with number of tips recorded by the data collector examined, and calibration information including the make/model of calibrator, volume of water used, and flow rate.

\section{Working Precipitation Gage Records}

A separate station analysis is necessary for precipitation gages operated for public use. The station analysis should be written following each inspection of the precipitation gage describing performance of the gage during that period. The station analysis should include results of calibration procedures, conditions of the screen and funnel at the time of inspection, as well as description of any estimates that were necessary because of lost data, data that has been determined to be inaccurate, or data which is subject to ice or snow in the collection cone or melting thereof. Data corrections should not be applied to precipitation gages even when the instrument is not in calibration, as described in Office of Surface Water Technical Memorandum 2006.01 (p. 11).

\section{Estimating Precipitation Record}

Estimation for any missing or erroneous record should be estimated as described in Office of Surface Water Technical Memorandum 2006.01 (p. 12). Estimates should only be performed on daily values of precipitation using an approved method with a description of methods used in the station analysis.

\section{Checking Precipitation Gage Records}

As with all other hydrologic records, each station analysis is subject to checking for errors in the data collection calculations and procedures. The primary duty of a record checker for a precipitation record is to ensure all calculations at the time of the gage calibration have been performed correctly, with a secondary responsibility of ensuring that all days of estimated data have been included for description in the station analysis.

\section{Reviewing Precipitation Gage Records}

Each record period is subject to a review process wherein the record reviewer examines the data for any discrepancies that the record worker missed. Comparison should be made to nearby gages with special attention on days of estimated record. Field notes must be examined for compliance with policy regarding calibrations and cleaning procedures.

\section{Storing and Archival of Hydrologic Data and Related Metadata}

Thorough documentation of qualitative and quantitative information describing each gaging station is required. This documentation, in the form of a station description, photographs, levels summaries, and an approved hydrologic record provides a permanent record of site characteristics, structures, 
equipment, instrumentation, elevations, location, and changes in conditions at each site.

\section{Station Descriptions}

A station description is prepared for each gaging station and becomes part of the permanent record for each station. It is USGS policy in Kansas that the station description is written when a gage is installed, and then maintained continually as changes to the station occur. The responsibility for ensuring that station descriptions are prepared correctly and in a timely manner is held by the Field Office Chief. Station descriptions are written and updated by the personnel who service each station. Station descriptions are reviewed continuously by the record reviewers, and updates are made when appropriate. Station descriptions are stored in the Station Information Management System (SIMS) at http://sims.water.usgs.gov/.

Station descriptions are written to include specific types of information in a consistent format (Kennedy, 1983, p. 2). The station description should include the following information:

- Description of the gaging structures, instruments and locations thereof

- List and description of reference marks used for surveying including location

- Establishment and history of the gaging site, including any changes to the location, datum, methods of instrumentation, regulation, and major changes to the control features (for example, removal or installation of low head dam, construction of levees, and so on)

- Description of the control features

- Description and location of the most commonly measured section

- Historical floods in the vicinity

- A road log may be included in the station description, but is not required if GPS navigation systems can adequately lead a person to the gaging location in all flow conditions. If a road log is not included then the station description must include the latitude and longitude of the gaging station. Files for use in Garmin brand GPS devices can be found stored on the network

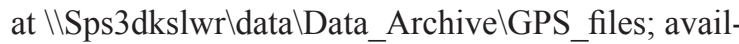
able on request.

\section{Photographs}

Photographs are used to document conditions and events at the gaging stations, conditions of the stream, as well as the physical set up of the gaging station. A slideshow display of multiple photographs is presented on NWISweb for each respective gaging site. It is the responsibility of the DBA to publish these photographs to the slideshow on NWISweb.

Photographs should be retained in the directory specific to each station in the data archive. For example, the directory location for photographs at the site Turkey Creek near Seneca can be found at \ligskqdewgs002\KS_Data_Dir\Station_Specific $\backslash 06814000 \_$Seneca $\backslash$ photos; available on request.

A list of features to be photographed includes, but is not limited to the following:

- Gage house, from a distance showing mast, solar panels, antenna and preferably indicating proximity to roads or other hazards

- Inside of gage house showing current equipment in use

- Reference gages

- The stream from mid-channel looking upstream, downstream and throughout the range of flows at the gage

- The stream in various seasonal conditions

- Low flow control

- High flow control

- Photographs of the control during the latest two visits to the gage, these are to be used for workers and reviewers to compare changes throughout a record period.

Photographic metadata should be used to describe the contents of each photograph, the photographer, and any relevant information. Using this metadata allows for a more efficient method of searching for photographs to use in reports and presentations.

\section{Documents at Gages}

At each gaging station there also is a station folder. This file contains the operation log, station description, current rating table, current levels summary, a data-collection platform (DCP) set-up sheet, job hazard analysis, traffic-control plan, and any other materials needed to operate and maintain the gage. It is the responsibility of the hydrographer servicing the gaging station to make sure these files are maintained and updated at the end of each year. 


\section{Other Data}

All other electronic data exist in the NWIS database for the KSWSC, or in the electronic archival directory ( \igskqdcwgs002ไKS_Data_Dir) for the KSWSC. Paper documents including field notes collected before implementation of digital note-taking methods are located in the back files of the respective field offices. Any new documents that are created on paper are digitally scanned and stored in the directory in the location pertinent to the given document.

\section{Safety}

Performing work activities in a manner that ensures the safety of personnel and others is the highest priority of the KSWSC. Beyond the obvious negative impacts that unsafe conditions can have on personnel such as accidents and personal injuries, they also can have a direct effect on the quality of surface-water data and data analysis. For example, errors may be made when attention to detail is compromised by an individual because of dangerous conditions creating distractions. So that personnel are aware of, and follow, established procedures and policies that promote all aspects of safety, the KSWSC communicates information and directives related to safety to all personnel by in-house training classes, memorandums, videos, a KSWSC safety Web site, and safety posters. Specific policies and procedures related to safety are in the facility protection plan, the traffic control plan, the flood plan, and job hazard analyses for individual streamgages. It is the responsibility of each employee to attend scheduled safety training, read all assigned safety material, and practice safe work habits at all times.

An individual has been designated as the KSWSC Safety Officer by the Director. The duties of the Safety Officer include knowing all safety requirements, organizing all safety inspections, organizing needed safety training, maintaining the safety Web page, and assisting in filing all required safety forms including accident reports. The Safety Officer attends regularly scheduled meetings with other Safety Officers to share information and review and discuss safety policy.

Personnel who have questions or concerns pertaining to safety, or who have suggestions for improving aspects of safety, should direct those questions, concerns, and suggestions to the KSWSC Safety Officer, Data Chief, or Director. Copies of the KSWSC traffic control plan and site-specific job hazard analyses should be kept in each field office and the respective gaging stations.

\section{Training}

Ensuring that personnel obtain knowledge of correct methods and procedures is a vital aspect of maintaining the quality of surface-water data. By providing appropriate training to personnel, the KSWSC increases the quality of work and reduces the likelihood of potential errors.

Available training is communicated to all KSWSC employees through the use of electronic mail and other oral or written means. Personnel are encouraged to seek appropriate training at all times and to identify needs or specific requests for training to the Data Chief or Director. Each year, the KSWSC senior staff discusses and prioritizes training for the following year. The result of this discussion is the KSWSC training plan. Room for contingency training exists in this plan and requests for training other than that on the training plan should be communicated to the Data Chief or Director. Needed safety training should be included in the annual training plan. New or inexperienced employees are given on-thejob training under the direction of the Data Chief, Field Office Chief, and other experienced hydrographers.

At least once every 2 years, the KSWSC holds a training week. Contents of the training week are determined by KSWSC managers and appropriate offsite trainers are brought in as needed.

\section{Summary}

Information included in the USGS Surface Water Quality-Assurance Plan for Kansas documents the policies and procedures that ensure high quality in the collection, processing, analysis, publication and storage of surface-water data. The roles and responsibilities of KSWSC personnel for carrying out these policies and procedures are presented, as are issues related to management of the computer database and issues related to employee safety and training.

\section{References Cited}

Arcement, G.J., and Schneider, V.R., 1989, Guide for selecting Manning's roughness coefficients for natural channels and flood plains: U.S. Geological Survey Water-Supply Paper $2339,38 \mathrm{p}$.

Barnes, H.B, 1967, Roughness characteristics of natural channels: U.S. Geological Survey Water-Supply paper 1849 , $213 \mathrm{p}$. 
Benson, M.A., and Dalrymple, Tate, 1967, General field and office procedures for indirect discharge measurements: U.S. Geological Survey Techniques of Water-Resources Investigations, book 3, chap. A1, 30 .

Bodhaine, G.L., 1982, Measurement of peak discharge at culverts by indirect methods: U.S. Geological Survey Techniques of Water-Resources Investigations, book 3, chap. A3, $60 \mathrm{p}$.

Campbell, P., 2014, Standard Operating Procedures for underice discharge measurements using ADCPs, 38 p.

Carter, R.W., and Davidian, Jacob, 1968, General procedures for gaging streams: U.S. Geological Survey Techniques of Water-Resources Investigations, book 3, chap. A6, 13 p.

Davidian, Jacob, 1984, Computation of water-surface profiles in open channels: U.S. Geological Survey Techniques of Water-Resources Investigations, book 3, chap. A15, 48 p.

Fulford, J.M., 1994, User's guide to SAC, a computer program for computing discharge by slope-are method: U.S. Geological Survey Open-File Report 94-360, 31 p.

Fulford, J.M., 1998, User's guide to the U.S. Geological Survey culvert analysis program, version 97-08: U.S. Geological Survey Water-Resources Investigations Report 98-4166, $70 \mathrm{p}$.

Kennedy, E.J., 1983, Computation of continuous records of streamflow: U.S. Geological Survey Techniques of WaterResources Investigations, book 3, chap. A13, 53 p.

Kennedy, E.J., 1984, Discharge ratings at gaging stations: U.S. Geological Survey Techniques of Water-Resources Investigations, book 3, chap. A10, 59 p.

Kenney, T.A., 2010, Levels at gaging stations: U.S. Geological Survey Techniques and Methods, book 3, chap. A19, 60 p.

Levesque, V.A., and Oberg, K.A., 2012, Computing discharge using the index velocity method: U.S. Geological Survey Techniques and Methods, book 3, chap. A23, 148 p.

Marintzer, L. S. and Foster, G. M., 2014, Traffic Control Handbook and Safety Policy for Work on Bridges and Around Roadways for the Kansas Water Science Center, 2014, 40 p.

Matthai, H.F., 1967, Measurement of peak discharge at width contractions by indirect methods: U.S. Geological Survey Techniques of Water-Resources Investigations, book 3, chap. A4, 44 p.

Mueller, D.S., 2013, extrap-Software to assist the selection of extrapolation methods for moving-boat ADCP streamflow measurements: Computers \& Geosciences, v. 54, p. 211-218.
Mueller, D.S., Wagner, C.R., Rehmel, M.S., Oberg, K.A, and Rainville, Francois, 2013, Measuring discharge with acoustic Doppler current profilers from a moving boat (ver. 2.0, December 2013): U.S. Geological Survey Techniques and Methods, book 3, chap. A22, 95 p. [Also available at http:// dx.doi.org/10.3133/tm3A22.]

Rantz, S.E., and others, 1982, Measurements and computation of streamflow, volumes 1 and 2: U.S. Geological Survey Water-Supply Paper 2175, 631 p.

Sauer, V.B., and Turnipseed, D.P., 2010 Stage Measurement at Gaging Stations: U.S. Geological Survey Techniques and Methods, book 3, chap. A7, 45 p.

Shearman, J. O., 1990, User's manual for WSPRO-A computer model for water surface profile computations: U.S. Federal Highway Administration Report, FHWA-IP-89-027, 187 p.

Turnipseed, D.P., and Sauer, V.B., 2010, Discharge measurements at gaging stations: U.S. Geological Survey Techniques and Methods, book 3, chap. A8, 87 p.

\section{Memorandums Cited}

The following memorandums were cited in this report. Copies of the memorandums are available to the public at the following Web site: http://water.usgs.gov/osw/pubs/ techmemos.html.

Office of Surface Water memorandum 87.05

Office of Surface Water memorandum 89.08

Office of Surface Water memorandum 92.10

Office of Surface Water memorandum 92.11

Office of Surface Water memorandum 93.07

Office of Surface Water memorandum 96.03

Office of Surface Water memorandum 96.04

Office of Surface Water memorandum 2006.01

Office of Surface Water memorandum 2010.07

Office of Surface Water memorandum 2011.08

Office of Surface Water memorandum 2012.01

Office of Surface Water memorandum 2012.04

Office of Surface Water memorandum 2014.03

Office of Surface Water memorandum 2014.04

Office of Surface Water memorandum 2014.06

Office of Surface Water memorandum 2014.08 
Publishing support provided by: Rolla Publishing Service Center

For additional information concerning this publication, contact: Director, USGS Kansas Water Science Center

4821 Quail Crest Place

Lawrence, KS 66049

(785) 842-9909

Or visit the Kansas Water Science Center Web site at: http://ks.water.usgs.gov 



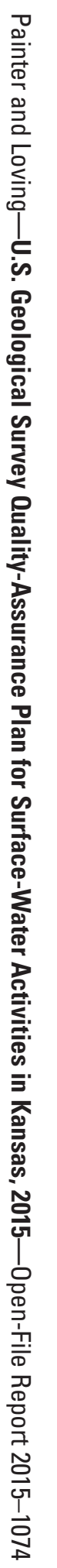

